\title{
Age-dependent neuroinflammation and cognitive decline in a novel Ala152Thr-Tau transgenic mouse model of PSP and AD
}

\author{
Astrid Sydow ${ }^{1,2^{*}+}$, Katja Hochgräfe ${ }^{2 \dagger}$, Stefanie Könen ${ }^{1}$, Daniela Cadinu², Dorthe Matenia', Olga Petrova ${ }^{1}$,
} Maria Joseph ${ }^{1,2}$, Frank Johannes Dennissen ${ }^{1}$ and Eva-Maria Mandelkow ${ }^{1,2,3^{*}}$

\begin{abstract}
Introduction: Mutations of Tau are associated with several neurodegenerative disorders. Recently, the Tau mutation A152T was described as a novel risk factor for frontotemporal dementia spectrum disorders and Alzheimer disease. In vitro Tau-A152T shows a decreased binding to microtubules and a reduced tendency to form abnormal fibers.

Results: To study the effects of this mutation we generated a mouse model expressing human full-length Tau with this mutation (hTau40 ${ }^{\mathrm{AT}}$ ). At young age (2-3 months) immunohistological analysis reveals pathological Tau conformation and Tau-hyperphosphorylation combined with Tau missorting into the somatodendritic compartment of neurons. With increasing age there is Tau aggregation including co-aggregates of endogenous mouse Tau and exogenous human Tau, accompanied by loss of synapses (especially presynaptic failure) and neurons. From 10 months onwards the mice show a prominent neuroinflammatory response as judged by activation of microglia and astrocytes. This progressive neuroinflammation becomes visible by in vivo bioluminescence imaging after crossbreeding of hTau40 ${ }^{\mathrm{AT}}$ mice and Gfapluciferase reporter mice. In contrast to other Tau-transgenic models and Alzheimer disease patients with reduced protein clearance, hTau40 ${ }^{\mathrm{AT}}$ mice show a strong induction of autophagy. Although Tau-hyperphosphorylation and aggregation is also present in spinal cord and motor cortex (due to the Thy 1.2 promoter), neuromotor performance is not affected. Deficits in spatial reference memory are manifest at $~ 16$ months and are accompanied by neuronal death.

Conclusions: The hTau40 ${ }^{\mathrm{AT}}$ mice mimic pathological hallmarks of tauopathies including a cognitive phenotype combined with pronounced neuroinflammation visible by bioluminescence. Thus the mice are suitable for mechanistic studies of Tau induced toxicity and in vivo validation of neuroprotective compounds.
\end{abstract}

Keywords: Progressive supranuclear palsy, Tau mutation, Mouse model, Inflammation, Autophagy, Behavior

\section{Introduction}

Tauopathies define a class of neurodegenerative diseases associated with the pathological deposition of Tau protein in different substructures of the human brain. The neuropathological profiles and clinical symptoms are rather heterogeneous and dependent on the affected brain areas [54]. The most prominent tauopathy is Alzheimer disease $(A D)$, where insoluble aggregated Tau fibers ("PHFs") are the major component of neurofibrillary

\footnotetext{
* Correspondence: sydow@mpasmb.desy.de; mandelkow@mpasmb.desy.de ${ }^{\dagger}$ Equal contributors

${ }^{1}$ German Center for Neurodegenerative Diseases (DZNE), Ludwig-Erhard-Allee 2, 53175 Bonn, Germany

${ }^{2}$ Max-Planck-Institute for Metabolism Research, Hamburg Outstation, c/o

DESY, Notkestrasse 85, 22607 Hamburg, Germany

Full list of author information is available at the end of the article
}

lesions. The pathology propagates from transentorhinal regions to the limbic system and neocortical areas as described by the Braak stages for $\mathrm{AD}$-patients and transgenic mice $[15,22,41,63]$. As a consequence of synapse loss and neuronal death in the affected brain areas, $\mathrm{AD}$ is clinically characterized by short- and longterm memory loss [103]. Other tauopathies include the group of frontotemporal dementias (FTD) with the major pathological subtypes of progressive supranuclear palsy (PSP), corticobasal degeneration (CBD), Pick disease $(\mathrm{PiD})$, argyrophilic grain disease (AgD), multiple system tauopathy with dementia (MSTD) and frontotemporal

C 2016 Sydow et al. Open Access This article is distributed under the terms of the Creative Commons Attribution 4.0 International License (http://creativecommons.org/licenses/by/4.0/), which permits unrestricted use, distribution, and reproduction in any medium, provided you give appropriate credit to the original author(s) and the source, provide a link to the Creative Commons license, and indicate if changes were made. The Creative Commons Public Domain Dedication waiver (http://creativecommons.org/publicdomain/zero/1.0/) applies to the data made available in this article, unless otherwise stated. 
dementia and parkinsonism linked to chromosome 17 (FTDP-17) [79]. Major risk factors for FTDs are mutations within the microtubule associated protein Tau (MAPT) gene located on chromosome 17 (17q21) [4]. Most MAPT mutations are clustered in exons 9-13, encoding for the Tau repeat domain and flanking regions responsible for microtubule (MT) binding. Consequently, these Tau mutations destabilize microtubules and enhance Tauaggregation since the $\beta$-sheet rich repeat domain plays a major role in Tau filament assembly [70].

Recently, a rare MAPT p.A152T mutation was identified as a novel risk factor among patients diagnosed with PSP, AD, PD, CBD and unclassifiable tauopathy presenting with atypical clinical and neuropathological features $[20,38,55,57,60]$. Besides p.A152T, several other $M A P T$ mutations cause clinical and neuropathological phenotypes resembling PSP, i.e. R5L, N279K, L284R, homozygous $\Delta$ N296, G303V, S305S, S352L and R406W, and an extended $\mathrm{H} 1$ haplotype $[8,90,113]$.

The MAPT p.A152T mutation is located in exon 7 encoding the N-terminal part or "projection domain" of Tau, which is far from MT binding domain [57]. In comparison to wild-type Tau, hTau $40^{\mathrm{AT}}$ is less efficient in stabilizing MT, it reduces the aggregation into filaments and enhances oligomeric structures in vitro [20]. Expression of hTau $40^{\mathrm{AT}}$ in human induced pluripotent stem cells (hIPSC) shows an increased Tau- fragmentation and phosphorylation leading to axonal degeneration [32]. However, it is still not known how the mutant hTau $40^{\mathrm{AT}}$ contributes to neurotoxicity.

To this end we generated a new mouse model expressing human full-length Tau (hTau40, 2N4R) with the point mutation A152T (hTau40 ${ }^{\mathrm{AT}}$ for short) and characterized the pathological and functional effects under physiological conditions. The transgenic hTau $40^{\mathrm{AT}}$ mice develop a progressive Tau pathology including Tau conformational changes, Tau-hyperphosphorylation and Tau-aggregation. This is accompanied by loss of synapses (especially presynaptic failure), neuronal death and upregulation of protein clearance mechanisms such as autophagy. In addition the expression of hTau $40^{\mathrm{AT}}$ causes a marked increase of astrocytic and microglia activity, indicating a strong neuroinflammatory response. In spite of panneuronal expression in the brain and spinal cord, hTau $40^{\mathrm{AT}}$ mice exhibit intact motor functions but develop cognitive decline at advanced age ( 16 mo). The study shows that hTau $40^{\mathrm{AT}}$-expression at low near-physiological levels (1-2-fold over endogenous Tau) is sufficient to induce a severe neuropathology leading to functional deficits and neurodegeneration in vivo, consistent with a neurotoxic gain of function. Thus the new tauopathy mouse model expressing hTau $40^{\mathrm{AT}}$ is suitable for mechanistic studies of Tau induced toxicity and for in vivo validation of neuroprotective compounds.

\section{Materials and methods} Generation of hTau $40^{\mathrm{AT}}$ mice

To achieve expression at moderate levels the transgene (human full-length Tau carrying the mutation A152T) was inserted into the ROSA26-locus [33] of C57BL/6 N embryonic stem (ES) cells and injected into BALB/c blastocysts (Taconic). Injected blastocysts were transferred into the uterine horn of pseudopregnant NMR1 females. Highly chimeric mice were bred to C57BL/6 N females. Germline transmission was identified by the presence of black offspring. The transgene expression is controlled by the neuron specific murine Thy1.2 promoter and occurs pan-neuronally in brain and spinal cord. The present study shows data of heterozygous hTau $40^{\mathrm{AT}}$ mice with identical C57BL/6 $\mathrm{N}$ background. Non-transgenic littermates were used as negative controls. All animals were housed and tested according to standards of the German Animal Welfare Act. hTau40 ${ }^{\mathrm{AT}}$ mice were identified by PCR using primers 5'AGCAC CCTTAGTGGATGAGG-3' and 5'-TTGTCATCGCTTCC AGTCC-3,' amplifying the human Tau target fragment.

\section{Biochemical analysis}

Sarcosyl extraction, total protein preparation and western blots analysis were performed as described [75]. Briefly, 3-40 $\mu \mathrm{g}$ of total protein or $3 \mu \mathrm{l}$ of sarcosyl extraction lysates from tissues (cortex, hippocampus, cerebellum, spinal cord) were separated on $10 \%$ SDS-gels or gradient gels $(4 \%-20 \%$, Biorad) and transferred to PVDFmembranes for detection with the following antibodies: K9JA (1:20000, Dako), 12E8 (pS262/pS356, 1:1000, a gift from Dr. P. Seubert, Elan Pharma, South San Francisco, CA), AT8 (pSer202/pThr205, 1:500, Thermo Scientific), PHF-1 (pS396/pS404, 1:50, a gift from Dr. P. Davies, Albert Einstein College of Medicine, NY), synaptophysin (1:20000, Sigma), PSD95 (1:2000, Dianova), NeuN (1:1000, Millipore), PSMD13 (1:1000, Abcam), Prot 20S C2 (1:1000, Abcam), LC3 (1:1000, Novus Biologicals), p62 (1:2500, Abnova), Iba1 (1:1000, WAKO), iNOS (1:1000, Abcam), CD11b (1:500, Novus) and GFAP (1:2000, Sigma). Blots were normalized by the concentration of ß-actin (1:20000, Sigma) or GAPDH (1:10000, Sigma), visualized with ECL Plus detection system (GE Healthcare) and analyzed by densitometry (LAS 3000/ChemiBis, AIDA software). Bars represent mean \pm SEM; $n=3-17$.

\section{Histological analysis}

Immunohistochemistry was performed with $5 \mu \mathrm{m}$ paraffin sections as described [75]. Tissue (brain and spinal cord) was fixed in histofix (Roth; 4 \% PFA, pH 7.4 for $24 \mathrm{~h}$ ) and dehydrated by a series of ethanol and chloroform. Sagittal brain and coronal spinal cord sections were incubated with primary antibodies prepared in $1 \%$ horse serum overnight at $4{ }^{\circ} \mathrm{C}$. The following antibodies 
were used: TauY9 (1:2000, Enzo), 12E8 (pS262/pS356, 1:2000) (a gift from Dr. P. Seubert, Elan Pharma, South San Francisco, CA), AT180 (pThr231/pSer235, 1:500, Pierce), AT8 (pSer202/pThr205, 1:500, Thermo Scientific), Alz-50 (1:50) and PHF-1 (pS396/pS404, 1:50) (Alz-50 and PHF-1 are gifts from Dr. P. Davies, Albert Einstein College of Medicine, NY), Iba1 (1:1000, Wako), GFAP (1:2000, Sigma), S100b (1:100000, Novus), IL1ß (1:25, SantaCruz), TLR2 (1:150, Millipore). Inflammatory markers like CD11b (1:5000, Serotec) and CD45 (1:500, Serotec) were analyzed using $20 \mu \mathrm{m}$ sagittal cryo sections. Counterstaining with hematoxylin (Roth) was performed according to the company's instructions. To visualize copathologies (neuroinflammation vs. Tau phosphorylation), sections were first incubated with antibodies against inflammatory markers and developed with Vectastain Universal Elite ABC kit + DAB (Vector Laboratories). Afterwards sections were re-incubated with primary antibodies against Tau-phospho epitopes and developed with Alkaline Phosphatase Universal kit + Alkaline Phosphatase substrate kit III (Vector Laboratories). Stainings were performed on paraffin sections of 4-6 mice, respectively, for genotype, age and antibody used.

\section{Fluoro Jade $\mathrm{C}$ staining}

To label neurodegeneration, $30 \mu \mathrm{m}$ floating sections of 3 WT and $3 \mathrm{hTau} 40^{\mathrm{AT}}$ mice were mounted on gelatin coated slides and rehydrated in a series of ethanol. Tissue autofluorescence was reduced by $0.06 \%$ potassium permanganate treatment for $15 \mathrm{~min}$. Washed slices were stored for $30 \mathrm{~min}$ in $0.001 \%$ Fluoro Jade C staining solution (Merck) in the dark. Rinsed and dried slides were immersed in xylene and coverslipped with Histokitt (Roth). Fluoro Jade C staining was analyzed using FITC filter settings.

\section{Gallyas silver staining}

$5 \mu \mathrm{m}$ paraffin sections were stained as published [15]. To visualize co-pathologies (neuroinflammation vs. Tauaggregation), Gallyas silver stained sections were incubated with antibodies against inflammatory markers and developed with Vectastain Universal Elite $A B C$ kit $+D A B$ (Vector Laboratories). Stainings were performed on paraffin sections of 4 mice, respectively for genotype and age.

\section{Thioflavin S staining}

Autofluorescence of $5 \mu \mathrm{m}$ paraffin brain sections was quenched [99], sections were incubated in $0.05 \%$ Thioflavin S (Sigma) for $8 \mathrm{~min}$, and excess Thioflavin $\mathrm{S}$ was removed by brief washing with $80 \% \mathrm{EtOH}$ and three washing steps in large volumes of tap water. Stained sections were stored in cold 3xPBS for $30 \mathrm{~min}$ to avoid photobleaching. After rinsing in 1xPBS, the tissue was counterstained with TOPRO-3 (nuclear marker; Invitrogen
Molecular Probes) and mounted in Aqua Poly/Mount (Polysciences Inc.). Analysis was performed on paraffin sections of 4 mice, respectively, for genotype and age.

\section{Golgi-staining and quantification of spines}

For Golgi-Cox impregnation of neurons [35], the FD rapid GolgiStain TM kit (FD NeuroTechnologies) was used according to the manufacturer's protocol. $80 \mu \mathrm{m}$ floating sections of transgenic and WT mice at 10 and 20 months of age were Golgi-impregnated and hippocampal pyramidal CA1- or CA3-neurons were used for quantification of dendritic spines as described [88]. For each mouse ( $n=2-3$ per group), $\sim 10$ neurons and $1-2$ secondary dendrites per neuron of $20-30 \mu \mathrm{m}$ lengths were quantified using ImageJ software $(\mathrm{NIH})$. Bars represent mean \pm SEM.

\section{In vivo bioluminescence imaging (BLI) of astrocyte activation} hTau40 ${ }^{\mathrm{AT} / \mathrm{C} 57 \mathrm{BL} / 6 \mathrm{~N}}$ mice were crossbred to $\mathrm{Tg}\left(\mathrm{Gfap}-\mathrm{luc}^{\mathrm{FVB} / \mathrm{N}}\right)$ reporter mice, expressing firefly luciferase under control of the murine Gfap-promoter [117]. Heterozygous, bigenic $\operatorname{Tg}$ (Gfap-luc: hTau40 $\left.{ }^{\mathrm{AT} / \text { mixed bkg }}\right)$ offspring $(n=18)$ were used to monitor luciferase activity as surrogate marker for astrocyte activation and Tau pathology. Heterozygous $\mathrm{Tg}$ (Gfap-luc ${ }^{\text {mixed }}$ bkg $)(n=9)$ were used as controls. Mice of both genders were imaged monthly starting at 3 months of age and continued until 18 months of age.

In vivo BLI was performed using an Ivis Lumina II system (Caliper Life Science) according to a standardized protocol. Ten minutes prior to each imaging session, mice received an intraperitoneal (i.p.) injection of $150 \mathrm{mg} /$ $\mathrm{kg}$ D-luciferin (Caliper Life Science) dissolved in sterile PBS and the heads of the animals were shaved. Mice were anesthetized using $2 \%$ isoflurane (Abbott) vaporized in a constant $\mathrm{O}_{2}$ flow. Anesthesia was maintained during the whole imaging session. Mice were placed into the heated, light-tight imaging chamber of the Ivis Lumina II and the ears were covered using black paper to shield unspecific luminescence signals. A sequence of 6 images taken in $2 \mathrm{~min}$ intervals starting at $10 \mathrm{~min}$ post i.p. injection was recorded using a highly sensitive charged coupled device camera. Images were analyzed using Living Image 4.0 software (Caliper Life Science). The bioluminescence emission was normalized and the surface radiance was displayed in photons per second per centimeter squared per steradian (photons $/ \mathrm{s} / \mathrm{cm}^{2} / \mathrm{sr}$ ). For quantification of bioluminescence signals, a region of interest (ROI) was defined to convert surface radiance (photons $/ \mathrm{s} / \mathrm{cm}^{2} / \mathrm{sr}$ ) into total flux of the bioluminescent source (photons/s). To compare bioluminescence signals of $\mathrm{Tg}$ (Gfap-luc: hTau $40^{\mathrm{AT} / \text { mixed }} \mathrm{bkg}$ ) and controls, total flux values of each experimental cohort were converted to percentage. Data represent 
mean values \pm standard error of the mean (SEM). Statistical comparisons were accomplished by two-way repeated ANOVA followed by a post hoc Bonferroni's multiple comparison test using Prism 5.0 (GraphPad Software). The accepted level of significance was $p<0.05$. Asterisks indicate significant differences between $\mathrm{Tg}$ (Gfap-luc: $\mathrm{hTau} 40^{\mathrm{AT} / \text { mixed } \mathrm{bkg}}$ ) and controls for each time point $\left(": p<0.05,{ }^{* * *}: p<0.01,{ }^{* * * * *}: p<0.001,{ }^{* * * * *}: p<0.0001\right)$.

\section{Housing conditions}

Mice were housed in groups of 2-5 animals under standard conditions $\left(23{ }^{\circ} \mathrm{C}, 40 \%-50 \%\right.$ humidity, food and water ad libitum) with a $12 \mathrm{~h}$ light/dark cycle (with light on from 7 a.m. to 7 p.m.). After 2 weeks of acclimatization and handling, behavior tests were carried out between 9 a.m. and 4 p.m. Transgenic hTau $40^{\mathrm{AT}}$ mice (mixed genders) were tested at 10 months $(n=18)$ and 16 months of age $(n=20)$ and compared to age-matched wild-type control littermates (mixed genders, $n=14$ and $n=11$ respectively).

\section{Morris water maze (MWM) MWM pretraining}

A 2 day pretraining protocol was conducted to habituate the mice to swimming and climbing onto a hidden platform (water temperature: $22{ }^{\circ} \mathrm{C}, 4$ trials/day, maximum duration/trial 60s, $60 \mathrm{~min}$ inter-trial interval). To avoid any interference with the MWM learning, the pretraining was performed in a different apparatus (Makrolon cage type III, $42 \times 26.5 \times 15.5 \mathrm{~cm}$ ) than used for the MWM (circular pool, diameter of $150 \mathrm{~cm}$ ). The position of the pretraining platform (diameter of $10 \mathrm{~cm}, 1 \mathrm{~cm}$ below the water surface) was randomized and could not be located by orientation via landmarks, thus mice had to swim at random to escape from the water.

\section{MWM acquisition and probe trials}

Spatial memory abilities were examined in the standard hidden-platform acquisition and retention version of the Morris water maze [77]. A $150 \mathrm{~cm}$ circular pool was filled with water opacified with non-toxic white paint (Biofa Primasol 3011), and kept at $22{ }^{\circ} \mathrm{C}$. Four positions around the edge of the tank were arbitrarily designated 1, 2, 3 and 4 thus dividing the tank into four quadrants: target $(\mathrm{T})$, right adjacent $(\mathrm{R})$, opposite $(\mathrm{O})$, and left adjacent (L). A $15 \mathrm{~cm}$ round platform was hidden $1 \mathrm{~cm}$ beneath the surface of the water at a fixed position in the center of target quadrant. The water maze was equipped with inner maze cues arranged in an asymmetrical manner to facilitate orientation. Each mouse performed 4 swimming trials per day (maximum duration 60s, 10 min inter-trial interval) for five consecutive days. Mice were started from 4 symmetrical positions in a pseudo-randomized order across trials. Mice that failed to find the submerged platform within 60s were guided to the platform, where they remained for $15 \mathrm{~s}$ before being returned to their home cage. The time required to locate the hidden escape platform (escape latency), the distance travelled (path length), and swimming speed (velocity) were determined. On acquisition day $3,4,5$, as well as 2 days after the acquisition phase ended (day 8), a probe trial was conducted with the platform removed and the search pattern of the mice was recorded for 60 s. On day 3, 4 and 5 the probe trial was performed between learning trial 2 and 3 . The following learning trials 3-4 were carried out with the platform returned to former position inside the target quadrant to avoid extinction. During acquisition and probe trials the Viewer II video tracking system was used to record and analyze behavior (Noldus).

Statistical comparisons between groups were accomplished by two-way repeated ANOVA followed by a post hoc Fisher LSD multiple comparison test. Stars presented in graphs indicate differences between hTau $40^{\mathrm{AT}}$ mice and wild-type littermates (MWM acquisition). For analysis of probe trials a two-tailed one sample t-test against chance level $(25 \%)$ or a one-way ANOVA with post hoc Newman-Keuls multiple comparison test was done. All data are presented as group mean values with standard error of mean (SEM), the accepted level of significance was $p<0.05$. Statistical comparisons were performed using STATISTICA 10.0 software (StatSoft Germany), graphs were designed using Prism 5.0 (GraphPad Software). ${ }^{*}: p<0.05,{ }^{* * *}: p<0.01,{ }^{* * * *:}: p<0.001$.

\section{Results}

\section{Generation of hTau $40^{\mathrm{AT}}$ mice}

To mimic pathological hallmarks of genetically provoked tauopathies, we created a novel transgenic mouse model expressing human full-length Tau (441aa, 2N4R) with the mutation A152T (hTau40 ${ }^{\mathrm{AT}}$ ), which has been linked to FTD spectrum disorders such as PSP [20] (Fig. 1a). Transgene insertion into the ROSA26-locus [14] under control of the neuron-specific murine Thy1.2 promoter [18] led to hTau $40^{\mathrm{AT}}$ expression at near-physiological levels in neurons of the brain and spinal cord. Heterozygous hTau $40^{\mathrm{AT}}$ protein levels were $\sim 2$-fold in cortex, $\sim 1$-fold in hippocampus, $\sim 3$-fold in spinal cord and $\sim 1.5$-fold in cerebellum in comparison to endogenous mouse Tau (mTau) (Fig. 1b, c). The uniform neuronal distribution of hTau $40^{\mathrm{AT}}$ was confirmed by stainings of brain and spinal cord sections using the human Tau specific antibody TauY9 (Fig. 1d). From 2 months of age onwards the hTau $40^{\mathrm{AT}}$ mice show an intense staining of CA3-mossy fibers (Fig. 1d11) as well as mislocalization of hTau $40^{\mathrm{AT}}$ protein into the somatodendritic compartment of cortical, hippocampal, spinal and cerebellar neurons (Fig. 1d9-10, 1d12-13). 


\section{a Tau expression cassette}
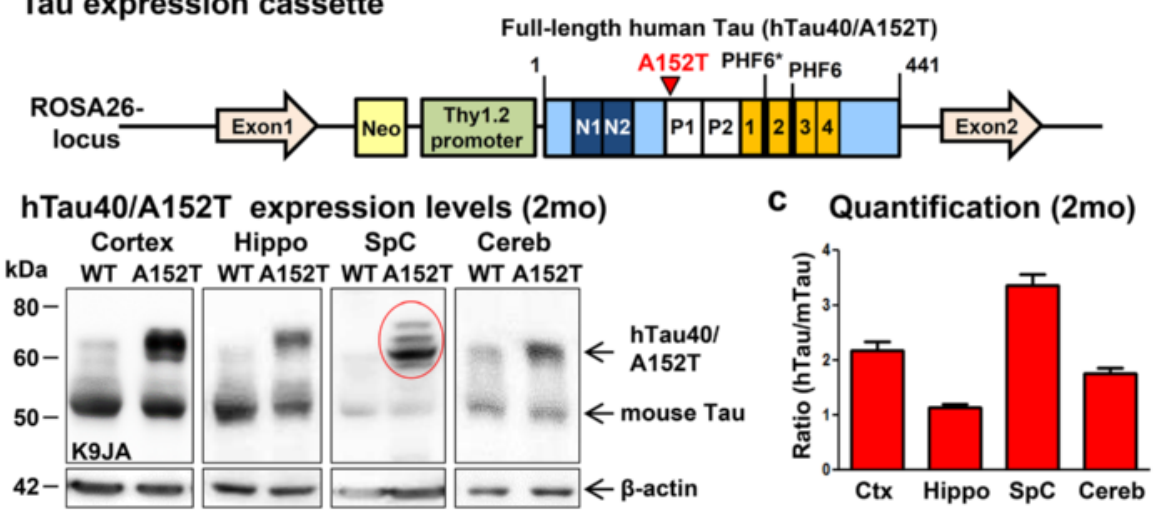

d hTau40/A152T expression pattern

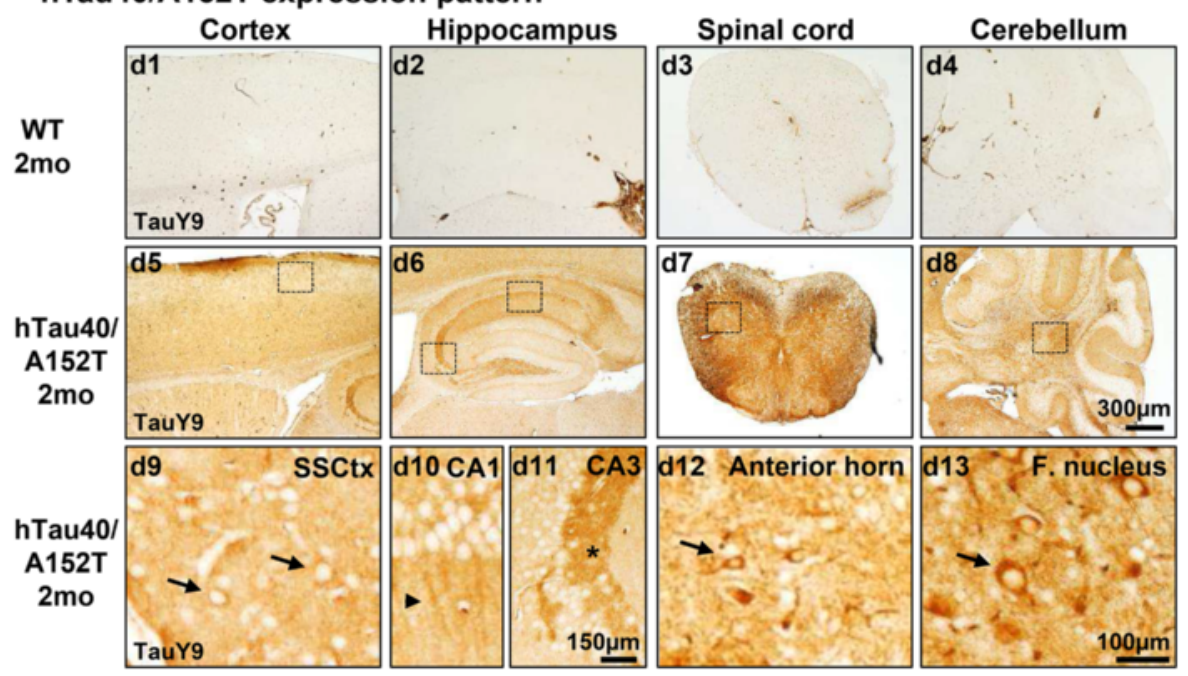

Fig. 1 Generation of human hTau40 AT mice with the Tau mutation A152T. a Illustration of the mutated hTau40 ${ }^{\text {AT }}$-gene located in the ROSA26-locus. Scheme represents human full-length Tau (hTau40) with highlighted A152T mutation (red), proline-rich domain (white, P1, P2), N-terminal inserts (dark blue, N1, N2) and aggregation-prone hexapeptide motifs (PHF6*, PHF6) in the repeat domain (orange, 1-4). hTau40 ${ }^{\mathrm{AT}}$-expression is controlled by the murine Thy 1.2 promoter. b Representative expression of hTau40 ${ }^{\mathrm{AT}}(\mathrm{Mr} \sim 67 \mathrm{kDa}$ ) and endogenous mouse Tau (Mr $\sim 45-55 \mathrm{kDa}$ ) in cortex, hippocampus, spinal cord and cerebellum of 2 months old hTau $40^{\mathrm{AT}}$ mice and age matched controls (WT) detected by the pan-Tau antibody K9JA. Note the slightly up-shifted human Tau in the spinal cord sample caused by hyperphosphorylation (red circle). B-actin serves as loading control. c Quantification of (b). Ratio of hTau40 ${ }^{\mathrm{AT}}$ to endogenous mTau indicates the hTau40 ${ }^{\mathrm{AT}}$ expression level in different brain regions, e.g. cortex $(\sim 2 \mathrm{x})$, hippocampus $(\sim 1 \mathrm{x})$, spinal cord $(\sim 3 \mathrm{x})$ and cerebellum ( 1.5x). Each bar shows mean \pm SEM of $n=17$ animals. $\mathbf{d}$ Uniform distribution of hTau40 ${ }^{\text {AT }}$ visualized by the human Tau specific antibody TauY9 in brain (cortex, hippocampus and cerebellum) and spinal cord of 2 months old hTau40 ${ }^{\mathrm{AT}}$ mice (d5-d8). Boxed areas with higher magnification (d9-d13) indicate mislocalization of hTau40 $0^{\mathrm{AT}}$ into cell bodies (arrows) and dendrites (arrowhead) and a strong immunoreactivity of mossy fibers in the CA3 hippocampal area (asterisk) in comparison to WT mice (d1-d4). WT: wild-type; A152T: hTau40 ${ }^{\mathrm{AT}}$ transgenic mouse strain; Ctx: cortex; Hippo: hippocampus; SpC: spinal cord; Cereb: cerebellum; SSCtx: somatosensory cortex; CA: cornu ammonis; F. nucleus: Fastigial nucleus; mo: months; Scale bars: $100 \mu \mathrm{m}$ (d9, d10, d12, d13), $150 \mu \mathrm{m}$ (d1 1), $300 \mu \mathrm{m}$ (d1-d8)

\section{Co-aggregation of exogenous hTau40 ${ }^{\mathrm{AT}}$ and endogenous mouse Tau}

Pathological stages of Tau-aggregation can be classified into early conformational changes (antibodies Alz-50 or MC-1 [53]), early stages of aggregation (sarcosyl-insoluble Tau, "pretangles"), and fully developed neurofibrillary tangles (NFTs, visualized by Gallyas silver and Thioflavin S). In heterozygous hTau $40^{\mathrm{AT}}$ mice an age-dependent reduction of sarcosyl-soluble hTau $40^{\mathrm{AT}}$ was observed from 5 to 20 months of age (Fig. 2a, c). At 5 months, the ratio of soluble Tau species (transgenic hTau $40^{\mathrm{AT}}$ vs. endogenous $\mathrm{mTau}$ ) was 1.7 and decreased to $\sim 1.4-1.3$ at $10-20$ months of age (Fig. 2c). Sarcosyl-insoluble fractions of 5, 10 and 20 months old transgenic mice contained both, hTau $40^{\mathrm{AT}}$ and $\mathrm{mTau}$, indicating a progressive coaggregation of exogenous human and endogenous mouse Tau (Fig. 2b, d).

Gallyas-silver positive Tau inclusions detected in cortical, hippocampal, cerebellar and spinal neurons of hTau $40^{\mathrm{AT}}$ mice were considered as fully developed NFTs, exhibiting 
a Sarcosyl-soluble Tau

K9JA A152T WT

$\begin{array}{lllll}\mathrm{K} 9 \mathrm{JA} & 5 & 10 & 20 & 20 \mathrm{mo}\end{array}$

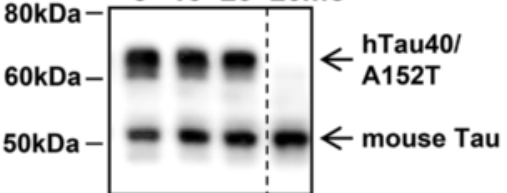

C Sarcosyl-soluble Tau

Ratio

hTau/mTau: $1.7 \quad 1.4 \quad 1.3$

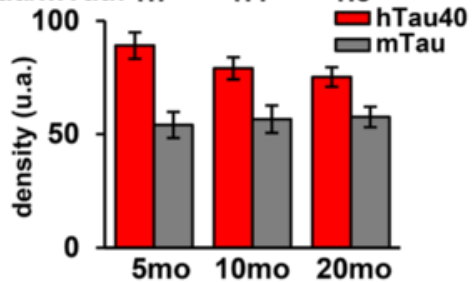

b Sarcosyl-insoluble Tau

K9JA A152T WT

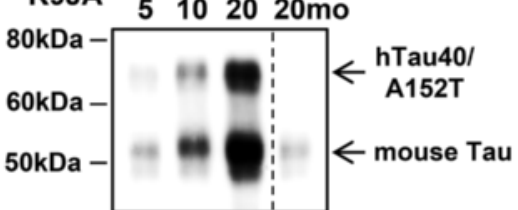

d Sarcosyl-insoluble Tau

Ratio

hTau/mTau: $0.69 \quad 0.67 \quad 0.67$

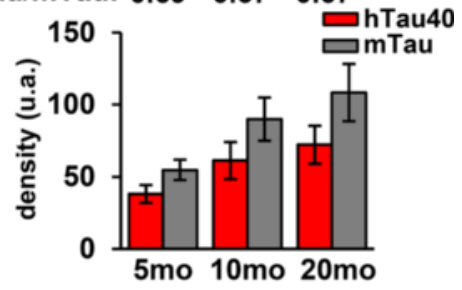

e NFT pathology (Gallyas silver staining)

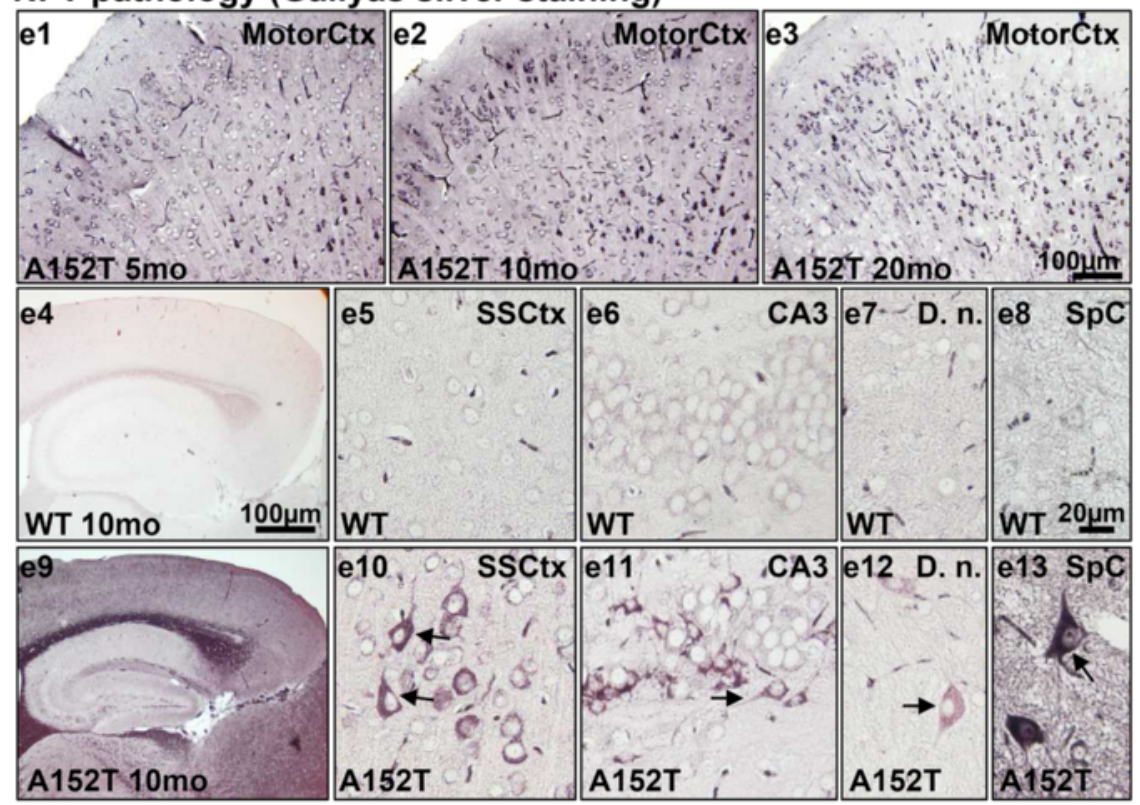

f NFT pathology (Thioflavin S staining)
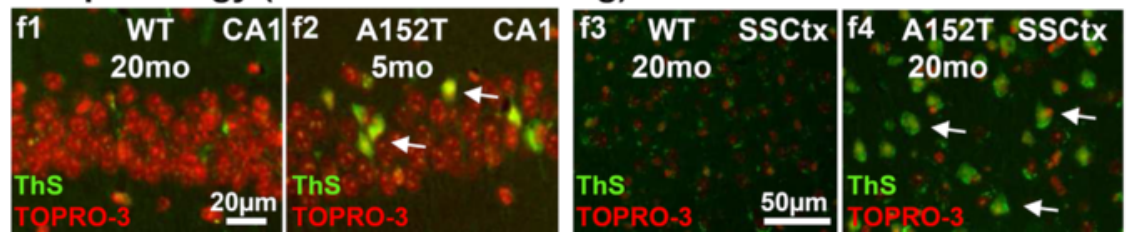

Fig. 2 (See legend on next page.) 
(See figure on previous page.)

Fig. 2 Progressive co-aggregation of endogenous mouse Tau and exogenous human hTau40 ${ }^{A T}$ in mice. a-b Western blot analysis using the pan-Tau antibody K9JA shows sarcosyl-soluble and sarcosyl-insoluble Tau species of hTau40 AT (upper band; Mr $\sim 67 \mathrm{kDa}$ ) and mouse Tau (lower band; $\mathrm{Mr} \sim 45-55 \mathrm{kDa}$ ). Note (a) the slight reduction of soluble hTau40 ${ }^{\mathrm{AT}}$ and (b) a progressive co-aggregation of insoluble mouse and human Tau in aging hTau $40^{\mathrm{AT}}$ mice. c Quantification of (a). Densitometric measurements of hTau40 (red bars) and mouse Tau (grey bars) indicate a reduction of soluble hTau $40^{\mathrm{AT}}$ with age (5-20mo) (note the declining ratio in aging transgenic mice). Each bar shows mean \pm SEM of $n=4$ animals. $\mathbf{d}$ Quantification of (b). Densitometric measurements of hTau $40^{\mathrm{AT}}$ (red bars) and mouse Tau (grey bars) indicate an increase of insoluble human hTau $40^{\mathrm{AT}}$ and mouse Tau with increasing age (5-20mo). Each bar shows mean \pm SEM of $n=4$ animals, error bars represent SEM. e Gallyas silver staining of different brain areas. (e1-e3) Progressive Tau aggregation in motor cortex of hTau40 AT mice with increasing age. Note NFTs with flame-shaped structure (arrows) in cortical (e10), hippocampal (e11), cerebellar (e12) and spinal (e13) neurons of 10 months old hTau40 AT mice, compared to silver-negative control (e4-e8). f Thioflavin S staining (green) and counterstaining with TOPRO-3 (red) of hippocampal CA1 pyramidal neurons ( $\mathrm{f2}$, arrows) and somatosensory cortical neurons ( $f 4$, arrows) confirms the presence of NFTs in hTau40 ${ }^{\mathrm{AT}}$ mice at 5 and 20 months of age and the absence of Tau-aggregates in WT mice (f1, f3). WT: wildtype; A152T: hTau40 $0^{\mathrm{AT}}$ transgenic mouse strain; SSCtx: somatosensory cortex; SpC: spinal cord; D.n.: Dentate nucleus; CA: cornu ammonis; mo: months; Scale bars: $20 \mu \mathrm{m}$ (e5-e8, e10-e13, f1-f2); $50 \mu \mathrm{m}$ (f3-f4); $100 \mu \mathrm{m}$ (e1-e4, e9)

the typical flame-shaped structure (Fig. 2e9-13). In comparison non-transgenic littermates were silver-negative (Fig. 2e4-8). The formation of NFTs started as early as 3 months of age in cortical brain regions of hTau $40^{\mathrm{AT}}$ mice (data not shown) and the number of neurons containing NFTs increased in an age-dependent manner (Fig. 2e1-3). The presence of NFTs in hippocampal and cortical neurons of young and old hTau $40^{\mathrm{AT}}$ mice was confirmed by Thioflavin S stainings (Fig. 2f2, f4). One major neuropathological hallmark of PSP patients is the abnormal deposition of NFTs inside glial cells, the so called "tuft-shaped astrocytes" or "oligodendral coiled bodies" [23]. However, no Tau inclusions inside astrocytes or oligodendrocytes were detected in hTau $40^{\mathrm{AT}}$ mice from 5 to 20 months of age; similar to the lack of tufted astrocytes in a patient with A152T-mutated Tau [57].

\section{$\mathrm{hTau} 40^{\mathrm{AT}}$ induces pathological hyperphosphorylation and conformational changes of Tau at young age}

In AD, PSP and other tauopathies, Tau undergoes hyperphosphorylation and conformational changes, accompanied by the translocation of pathological Tau from the axonal to the somatodendritic compartment of neurons $[16,70]$. These changes are also observed in hTau $40^{\mathrm{AT}}$ mice as early as 3-4 months of age, viz. hyperphosphorylation [12E8 (pS262/pS356), AT180 (pT231/pS235), AT8 (pS202/pT205), PHF-1 (pS396/pS404)] and pathological conformation of Tau (Alz-50) appeared in hippocampal mossy fibers (asterisks, Fig. 3b2-f2), and in cell bodies and dendrites of hippocampal, cortical and spinal neurons (arrows, Fig. 3b2-f2, b4-f4, b6-f6), indicating missorting of pathological Tau in young hTau $40^{\mathrm{AT}}$ mice. The number of cortical neurons bearing hyperphosphorylated Tau (e.g. 12E8-, AT8- and PHF1-Tau) increased progressively with age (Additional file 1: Figure S1a-c). Analysis of hippocampal brain lysates confirmed the increase of hyperphosphorylated exogenous and endogenous Tau species with age (Fig. 4a-b). By contrast, the degree of phosphorylation at the 12E8 and PHF1 sites remained stable or decreased in 20 months old hTau $40^{\mathrm{AT}}$ mice, reflecting a potential correlation with progressive neuronal death (Fig. 9e-g).

\section{The A152T mutation correlates with pronounced neuroinflammation}

Inflammatory processes play a major role in neurodegenerative diseases, but it is unclear whether neuroinflammation is the cause or the response to pathological events. Due to various toxic brain insults (e.g. aberrant protein deposition and neurodegeneration), microglial cells and astrocytes become activated, undergo morphological changes and change their protein expression pattern [72]. To address the question whether neuroinflammatory processes contribute to the pathogenesis of hTau $40^{\mathrm{AT}}$ mice, we probed brain sections with antibodies against several inflammatory proteins (Fig. 5). Relative to age-matched WT mice, 10 months old hTau $40^{\mathrm{AT}}$ mice show a prominent hippocampal and cortical astrocytosis and microgliosis with higher numbers of GFAP- and S100b-positive activated astrocytes and Iba1-positive microglia (Fig. 5a1-8). Although the microglia observed in the hippocampus (especially in the DG and CA3 regions) displayed an activated morphology with retracted, thicker processes (Fig. 5a8), only a few phagocytic microglial cells were detected in aged hTau $40^{\mathrm{AT}}$ mice (Additional file 1: Figure S6). The presence of activated microglia was confirmed by various microglial antigens, including CD45 and CD11b, from 5 months of age onwards (Fig. 5a10, a12). At 10 months, most CA1 neurons were positive for the pro-inflammatory cytokine IL1ß (Fig. 5a14). In addition, glial cells showed immunoreactivity against Toll-like receptor-2 (TLR2) (Fig. 5a16), indicating a potential activation of the TLR2-pathway.

By contrast, the majority of microglia in age-matched WT mice exhibited a ramified morphology with small somata and fine cellular processes (Fig. 5a7), characteristic of resting microglia. In addition, WT mice were immune-negative for microglia antigens (CD45, CD11b), pro-inflammatory cytokines (IL1ß) and TLR2 (Fig. 5a9,11,13,15). At 12 months of age, hTau $40^{\mathrm{AT}}$ 


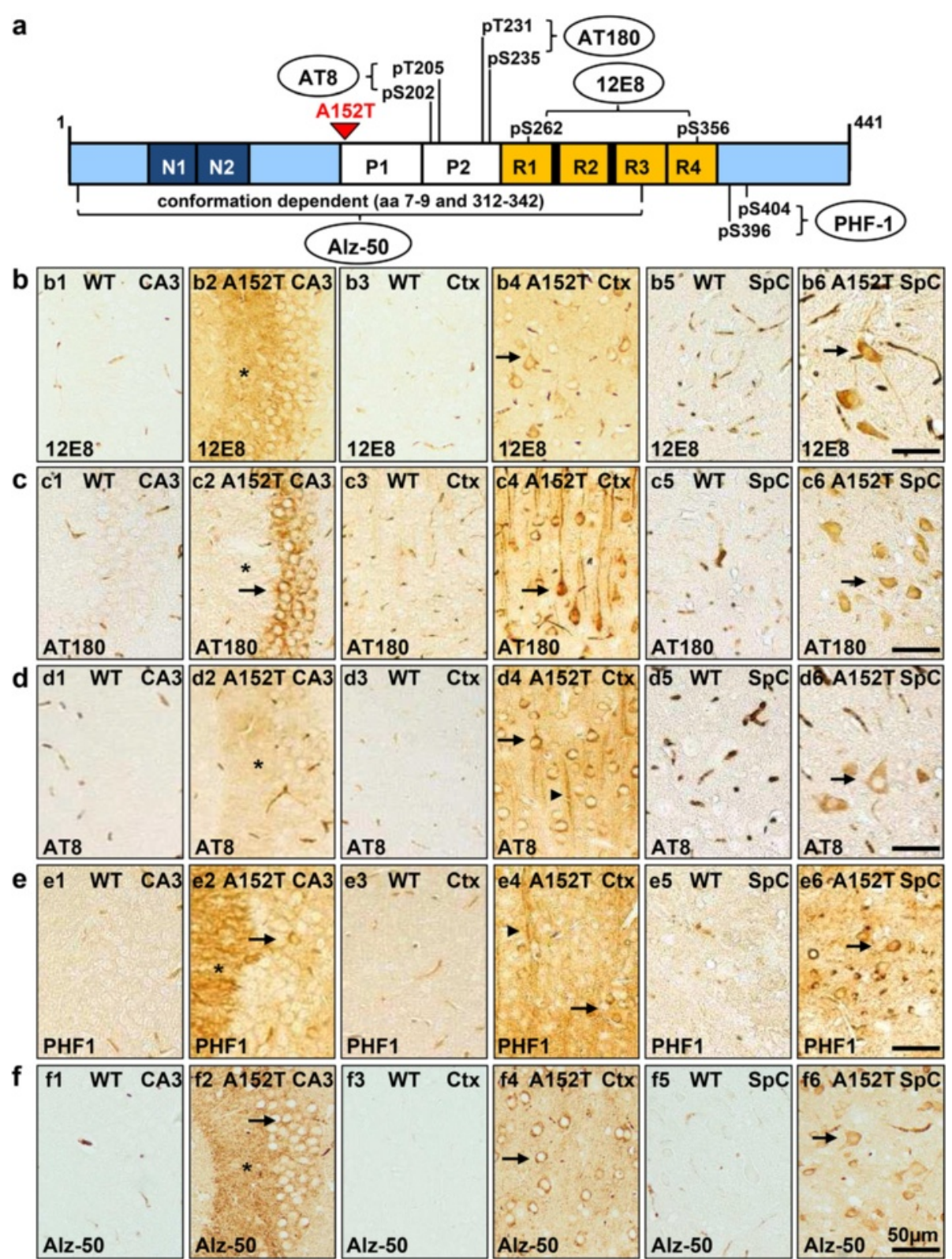

Fig. 3 Expression of hTau40 ${ }^{\mathrm{AT}}$ induces pathological hyperphosphorylation and conformational changes of Tau in 3-5 months old hTau40 $0^{\mathrm{AT}}$ mice. a Illustration of human full length Tau with highlighted phospho-Tau antibody-epitopes AT180 (pThr231/pSer235), AT8 (pSer202/pThr205), 12E8 (pS262/pS356) and PHF1 (pSer396/pSer404) and pathological Tau conformation recognized by antibody Alz-50 (aa 7-9 + 312-342). b-f Hyperphosphorylated, mislocalized and conformationally changed Tau in brain and spinal cord of 3-5 months old hTau40 ${ }^{\mathrm{AT}}$ mice detected by antibodies: (b) 12E8, (c) AT180, (d) AT8, (e) PHF1 and (f) Alz-50. Note Tau missorting into the somatodendritic compartment of hippocampal, cortical and spinal neurons (arrows). Asterisks indicate localization of phosphorylated and conformationally changed Tau in the stratum lucidum. In WT mice, areas CA3, cortex and spinal cord are non-reactive for 12E8, AT180, AT8 and PHF1 (b-e1, b-e3, b-e5). Pathological Tau conformation identified by Alz-50 antibody in brain ( $\mathrm{f2}$ (asterisk = CA3-mossy fibers), f4) and spinal cord (f6) of hTau40 ${ }^{\mathrm{AT}}$ mice compared to WT littermates (f1, f3, f5). WT: wild type; A152T: hTau40 ${ }^{A T}$ transgenic mouse strain; Ctx: cortex; SpC: spinal cord; CA: cornu ammonis; Scale bar: 50 um (b1-f6)

mice demonstrated an overall increase of neuroinflammatory protein levels relative to age-matched WT mice in cortical brain extracts (Fig. 5c, GFAP: $+40 \%$, Iba1: $+20 \%$, iNOS: $+150 \%$, CD11b: $+40 \%$ ).

Progressive neuroinflammation in hTau $40^{\mathrm{AT}}$ mice was age-dependent as judged by increasing numbers of reactive astrocytes in hippocampus (Fig. 6c) and increasing amounts of GFAP protein levels in cortex brain extracts (Fig. $6 \mathrm{~d}$ and e, GFAP: $+70 \%$ for 18 months old hTau $40^{\mathrm{AT}}$ mice relative to age-matched WT mice).

The upregulation of Gfap expression is a widely accepted marker of astrogliosis [72] and reporter strains optimized 


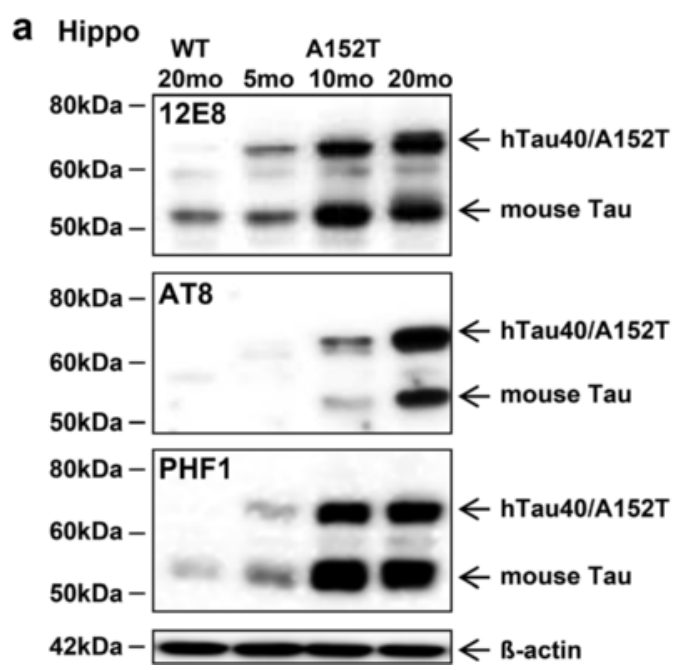

\section{b Quantification}
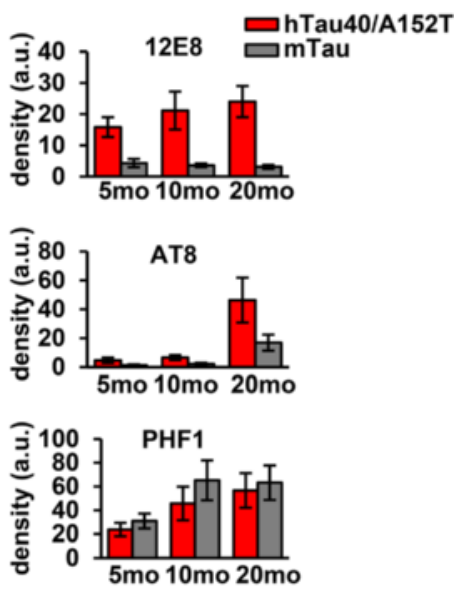

Fig. 4 Progressive hyperphosphorylation of Tau in aging hTau40AT mice (5-20mo). a Western blot analysis using phospho-Tau antibodies (12E8, AT8, PHF1) on hippocampal extracts of 5-20 months old hTau40 AT compared to 20 months old WT mice. b Quantification of (a). Densitometric analysis of $\mathrm{hTau}_{4} 0^{\mathrm{AT}}$ (red bars) and mouse Tau (grey bars) indicate an increase of hyperphosphorylated human hTau40 ${ }^{\mathrm{AT}}$ and mouse Tau in aging hTau40 ${ }^{\mathrm{AT}}$ mice (5-20mo). Each bar shows mean \pm SEM of $n=4$ animals. B-actin serves as loading control. WT: wild type; A152T, hTau40 ${ }^{\mathrm{AT}}$ transgenic mouse strain; mo: months, a.u.: arbitrary units

for non-invasive in vivo bioluminescence imaging (BLI) of neuroinflammation are available [reviewed in [46]]. In $\operatorname{Tg}$ (Gfap-luc) mice [117] luciferase is expressed upon induction of the murine Gfap promoter. Consequently, crossbreeding of $\mathrm{Tg}$ (GFAP-luc) mice with hTau $40^{\mathrm{AT}}$ mice allows longitudinal monitoring and quantification of astrocyte activation by in vivo BLI during the disease progression, similar to the monitoring of prion infectivity in prion-inoculated GFAP-luc mice [102].

At 3 months of age, hTau $40^{\mathrm{AT}}$ transgenic mice exhibited no overt signs of neuroinflammation as judged by histology (data not shown). Thus bioluminescence emission at 3 months of age was considered as background luciferase activity indicating the basal expression level of the Gfap promoter, which was defined as $100 \%$. At 5 months of age, bigenic $\mathrm{Tg}$ (Gfap-luc: hTau $40^{\text {AT/mixed bkg }}$ ) demonstrated a significant rise in luciferase activity to $150 \%$ as compared to the baseline Gfap promoter activity. After this initial upregulation, a further increase of Gfapdriven luciferase activity was observed in $\operatorname{Tg}$ (Gfap-luc: $\mathrm{hTau} 40^{\mathrm{AT} / \text { mixed bkg }}$ ) mice reaching a plateau of $\sim 180 \%$ at the age of 14 months. In contrast, luciferase activity in the brains of $\mathrm{Tg}$ (Gfap-luc $\left.{ }^{\text {mixed } \mathrm{bkg}}\right)$ control animals remained stable over time ( 100-120 \%; Fig. 6a-b). The results demonstrate a strong upregulation of astrocyte activation in response to expression and accumulation of toxic hTau $40^{\mathrm{AT}}$.

Co-stainings of neuroinflammation and Tau-phosphorylation or neuroinflammation and Tau-aggregation demonstrated the accumulation of astrocytes and microglia in the surrounding of AT8-positive and NFT-bearing neurons (Fig. 7a, b), indicating a direct correlation of Tau pathology and neuroinflammatory changes in hTau $40^{\mathrm{AT}}$ mice.

Protein degradation systems are altered in $\mathrm{hTau} 40^{\mathrm{AT}}$ mice Impaired protein quality control and impaired clearance via ubiquitin-proteasome and autophagosome-lysosome pathways are known to cause abnormal accumulation of disease-related proteins, which are deposited in intracellular or extracellular aggregates $[21,47,71]$.

At 20 months of age hTau $40^{\mathrm{AT}}$ mice showed an activation of the autophagosome-lysosome pathway (Fig. 8b, LC3II: $+60 \%$, p62: $-35 \%)$ and an inhibition of the ubiquitin-proteasome pathway (Fig. 8b, PSMD13 [regulatory subunit of the $26 \mathrm{~S}$ proteasome]: $-65 \%$, Proteasome $20 \mathrm{~S} \mathrm{C2:}-35 \%)$ in cortex extracts as compared to agematched WT littermates.

\section{Synaptic and neuronal loss in hippocampus and cortex of aged $\mathrm{hTau} 40^{\mathrm{AT}}$ mice}

One of the earliest changes occurring in AD is synaptic loss which correlates with the progression of cognitive decline in patients [106]. To check whether pre- and post-synaptic proteins were influenced by the accumulation of Tau in hTau $40^{\mathrm{AT}}$ mice, we probed hippocampal and cortical brain extracts of $\sim 12$ months old mice with antibodies against synaptic markers (Fig. 9a). This revealed a dramatic decrease of presynaptic synaptophysin (Fig. 9b, hippocampus: $-50 \%$, cortex: $-40 \%$ ), whereas post-synaptic PSD95 was less affected (Fig. 9b, hippocampus: $-10 \%$, cortex: $-35 \%$ ). The decrease of synaptophysin 


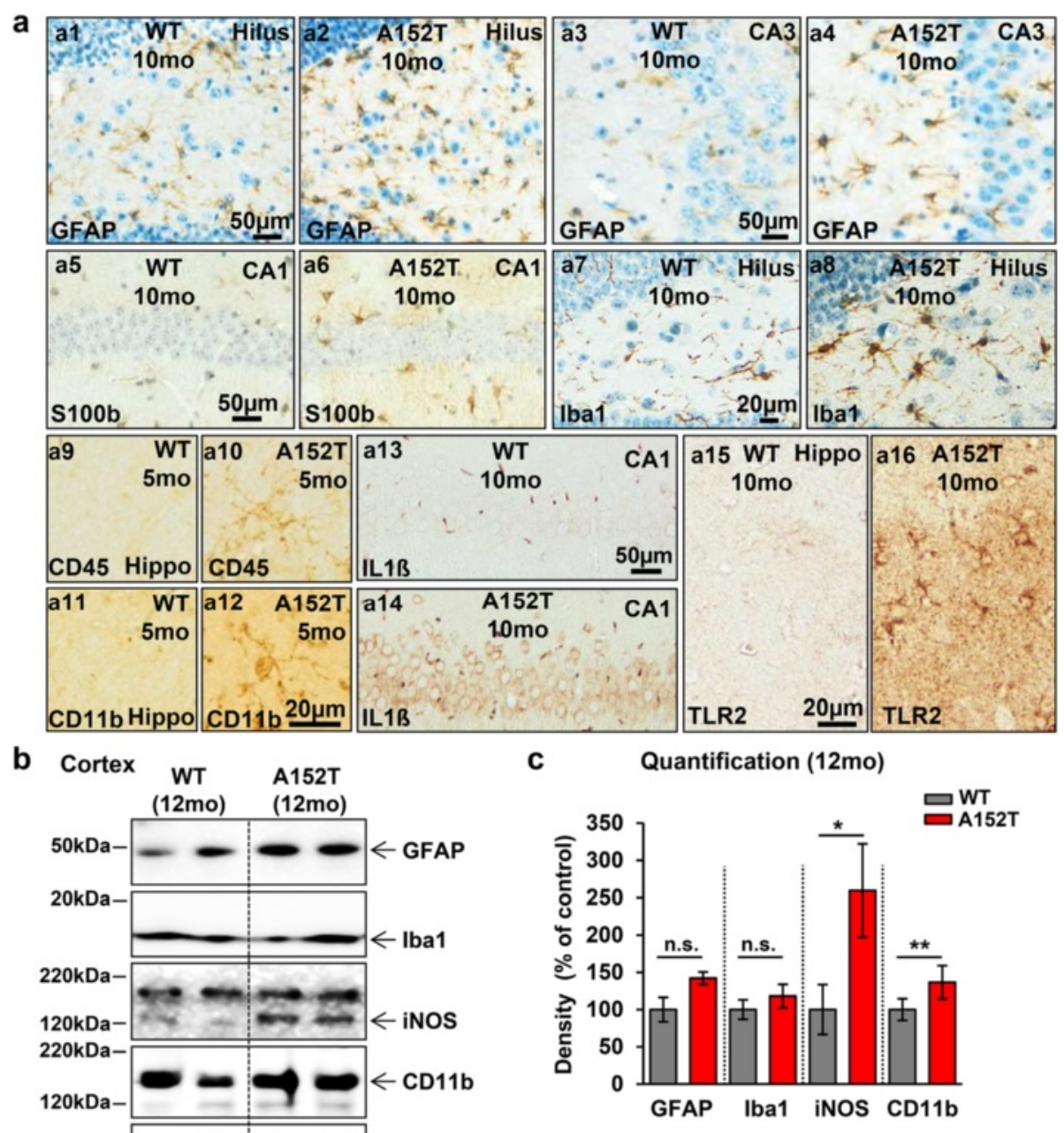

Fig. 5 Activation of microglia and astrocytes in hTau40 ${ }^{A T}$ mice. a Brain sections of hTau40 ${ }^{A T}$ and WT mice stained with antibodies against GFAP (a1-4), S100b (a5-6), Iba1 (a7-8), CD45 (a9-10), CD11b (a11-12), IL1ß (a13-14) and TLR2 (a15-16) and partly counterstained with hematoxylin (blue). Prominent astrogliosis detected by GFAP and S100b occurs particularly inside the hippocampus formation, demonstrated by higher numbers of reactive astrocytes in hilus (a2), CA3 (a4) and CA1 (a6) of hTau40 ${ }^{\mathrm{AT}}$ mice, compared to aged-matched WT mice (a1, a3, a5). Iba1 staining indicates microgliosis in 10 months old hTau40 ${ }^{\mathrm{AT}}$ mice (a8) compared to WT (a7). Note that microglia of hTau40 ${ }^{\mathrm{AT}}$ mice show an activated non-phagocytic phenotype with retracted, thicker processes (a8) compared to resting microglial cells of WT mice (a7). Activated microglia are detected by CD45 (a10) and CD11b (a12) at 5 months of age in hTau40 AT mice, whereas WT mice show no reaction (a9 and a11). Additionally, 10 months old hTau40 ${ }^{\mathrm{AT}}$ mice show IL1ß-positive pyramidal CA1-neurons (a14) and TLR2-immunoreactive glial cells (a16) in the hippocampus, compared to non-reactive WT mice (a13, a15). b Western blots of cortical extracts indicate increased levels of GFAP, Iba1, iNOS and CD11 b in hTau40 ${ }^{\mathrm{AT}}$ mice compared to WT mice. B-actin serves as loading control. c Densitometric analysis of western blots (b) for inflammatory proteins (GFAP, Iba1, iNOS and CD11b), all normalized to $B$-actin. The red bars indicate an increase of neuroinflammatory processes due to hTau $40^{A T}$-expression. Statistics: two-sided t test or Mann-WhitneyU-test indicate significant differences between WT and hTau40 ${ }^{\mathrm{AT}}$ mice $\left(*: p<0.05 ;{ }^{*}: p<0.01\right)$. Each bar represents mean \pm SEM of $n=4$ animals. WT: wildtype; A152T: hTau40AT transgenic mouse strain; CA: cornu ammonis; mo: months; IL1B, interleukin 1 beta, TLR2, Toll like receptor 2; iNOS, inducible nitric oxide synthase; n.s., not significant; Scale bars: $20 \mu \mathrm{m}$ (a7-12, a15-16), 50 um (a1-6, a13-14)

suggests a strong pathological effect of hTau $40^{\mathrm{AT}}$ at the pre-synapse rather than at the post-synapse. The mild defect of the post-synapse was consistent with spine counts of CA1-apical dendrites, which showed no significant differences in spine numbers between WT and cognitive unimpaired hTau $40^{\mathrm{AT}}$ mice at 10 months of age (Additional file 1: Figure S2a-b). By contrast, at more advanced age (20 mo) spine counts of cognitively impaired hTau $40^{\mathrm{AT}}$ mice demonstrated a highly significant decrease (reduction in CA1: $-35 \%$ and CA3: $-25 \%$ ) compared to age-matched WT mice (Fig. 9c-d). Additionally, neurodegeneration and neuronal loss were observed in the hippocampus and cortex of hTau $40^{\mathrm{AT}}$ mice from 12 months onwards as visualized by Fluoro Jade $C$ staining (Fig. 9e) and a reduction of NeuN protein levels at older ages (Fig. 9f-g; hTau $40^{\mathrm{AT}}$ mice: $-40 \%$ ). 

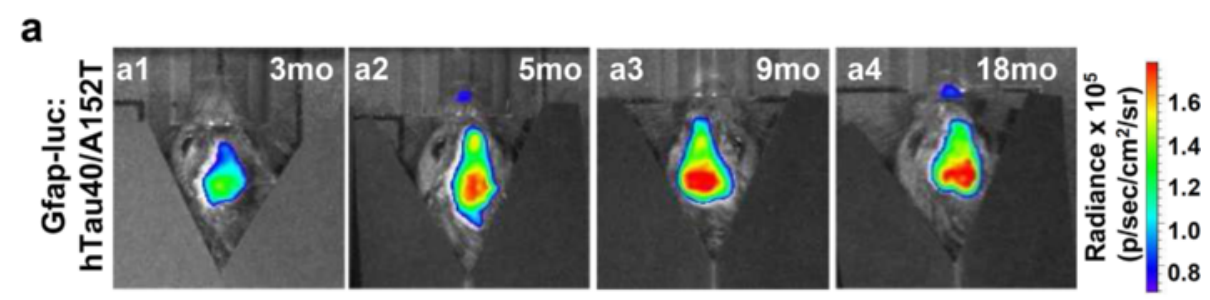

b

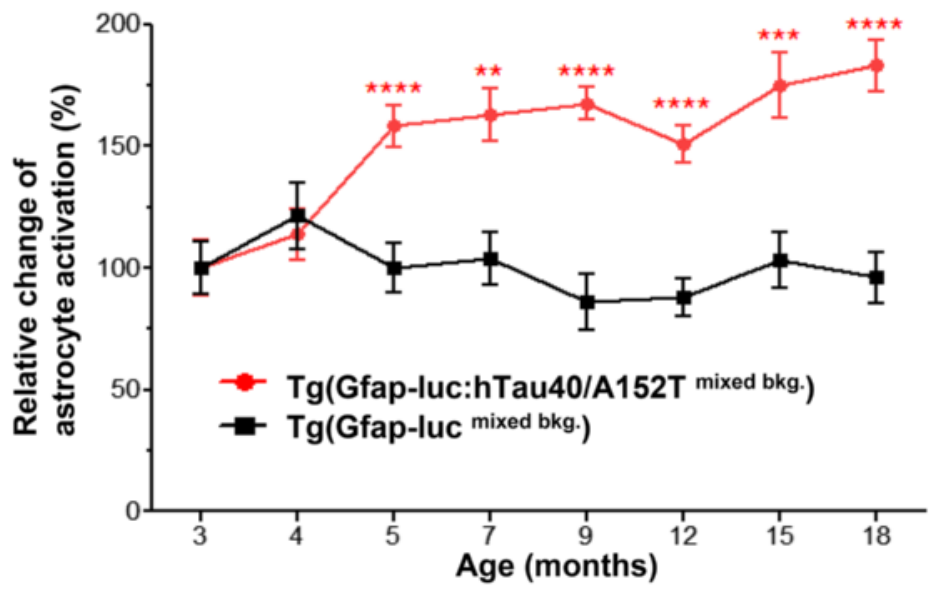

C

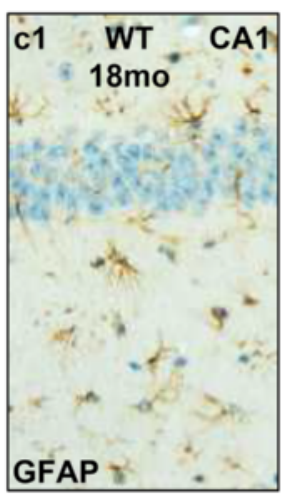

d

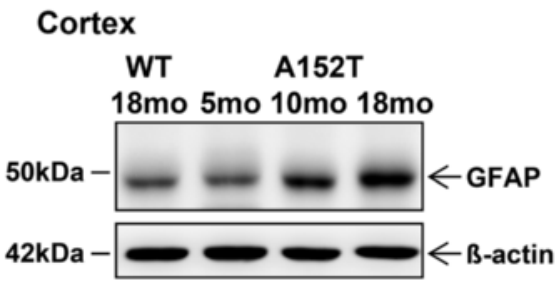

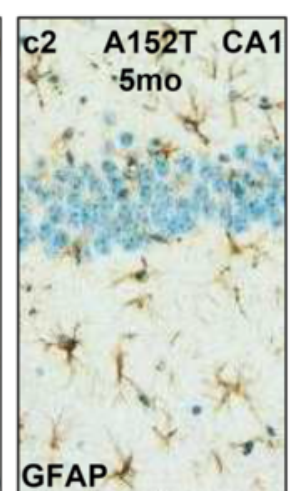

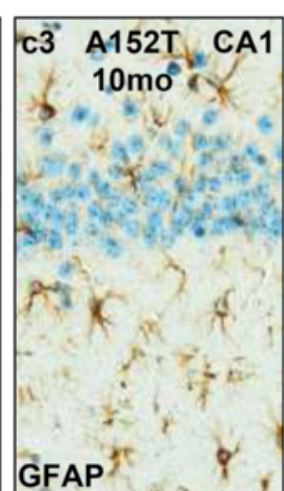

e

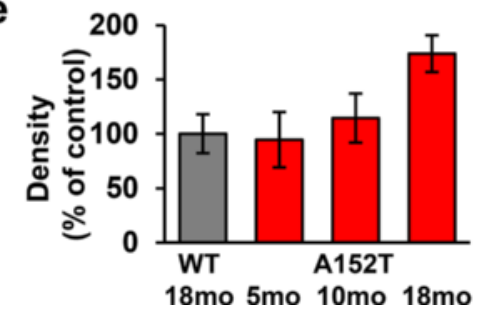

Fig. 6 (See legend on next page.) 
(See figure on previous page.)

Fig. 6 In vivo bioluminescence imaging (BLI) shows activation of astrocytes in response to aggregation of Tau. a Representative BLI signals emitted

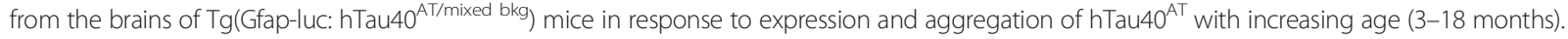
b Change of astrocyte activation (\%) as measured by in vivo BLI of luciferase activity. Data represents mean brain bioluminescence intensities ( \pm SEM) obtained from Tg(Gfap-luc: hTau40AT/mixed bkg) mice (red circles, $n=18$ ) in comparison to Tg(Gfap-luc ${ }^{\text {mixed bkg }}$ ) control animals (black squares, $n=9$ ) at 3-18 months of age. Gfap-driven luciferase activity is strongly increased in Tg(Gfap-luc: hTau40AT/mixed bkg) mice from 5 months of age onwards in comparison to control groups, demonstrating an upregulation of astrocyte activation, which correlates with the aggregation of toxic hTau40 ${ }^{\mathrm{AT}}$. Two-way repeated measures ANOVA reveals highly significant group differences between Tg(Gfap-luc: hTau40 $\left.{ }^{\mathrm{AT} / \mathrm{mixed}} \mathrm{bkg}\right)$ and control groups $\left(p<0.0001, F_{(2,199)}=33.46\right)$ and significant effect of interaction $\left(p=0.0001, F_{(12,199)}=3.43\right)$ and time $\left(p=0.033, F_{(6,199)}=2.33\right)$. Asterisks indicate levels of significance between Tg(Gfap-luc: hTau40 AT/mixed bkg) mice and Tg(Gfap-luc ${ }^{\text {mixed bkg }}$ ) control animals as determined by post-hoc analysis. ${ }^{*}: p<0.05,{ }^{* *}: p<0.01,{ }^{* * *}: p<0.001,{ }^{* * * *}: p<0.0001 ;$ mo, months of age; bkg, genetic background. c-e Progressive astrogliosis in hTau40 ${ }^{\mathrm{AT}}$ mice with increasing age. c Paraffin sections of 5 to 18 months old hTau40 ${ }^{\mathrm{AT}}$ and 18 months old WT mice were stained with GFAP (brown) and hematoxylin (b/ue). The majority of astrocytes of 18 months old hTau40 ${ }^{A T}$ mice shows an activated morphology (c4) compared to aged matched WT mice (c1) and younger hTau40 AT mice (c2-3). $\mathbf{d}$ Western blot of cortical extracts demonstrates a progressive GFAP upregulation in hTau40 AT mice (time course 5, 10 and 18 months) compared to 18 months old WT mice. $\beta$-actin serves as loading control. e Densitometric analysis of western blot $(\mathbf{d})$, normalized to $\beta$-actin. The red bars indicate a progressive astrogliosis in $\mathrm{hTau} 4 \mathrm{O}^{\mathrm{AT}}$ mice with increasing age compared to old WT mice. Each bar shows mean \pm SEM of $n=3$ animals. WT: wildtype; A152T: hTau40 ${ }^{\text {AT }}$ transgenic mouse strain; CA: cornu ammonis; mo: months; Scale bar: $50 \mu \mathrm{m}$ (c1-c4)

In conclusion, hTau $40^{\mathrm{AT}}$ mice show a strong defect of pre-synapses already at 12 months, whereas the postsynapse is only weakly affected at this stage, and damage becomes pronounced only at a later time point.

\section{Accumulation of $\mathrm{hTau} 40^{\mathrm{AT}}$ correlates with cognitive but not motoric deficits at advanced age} Transgenic hTau $40^{\mathrm{AT}}$ mice did not show abnormal motoric deficits up to 20 months of age. To show this, a detailed analysis was carried out at 10 and 16 months of age to characterize potential behavioral alterations caused by the expression and accumulation of hTau $40^{\mathrm{AT}}$. In the spinal cord, despite a $\sim 3$-fold overexpression of hTau $40^{\mathrm{AT}}$ and overt Tau-related pathological changes, we did not detect any motor deficiencies in a Rotarod test (Additional file 1: Figure S4) up to 16 months of age. In addition hTau $40^{\mathrm{AT}}$ mice did not exhibit any gait abnormalities in comparison to controls as determined by a Catwalk digital foot print analysis for single paw and inter-limb coordination (Additional file 1: Figure S5).
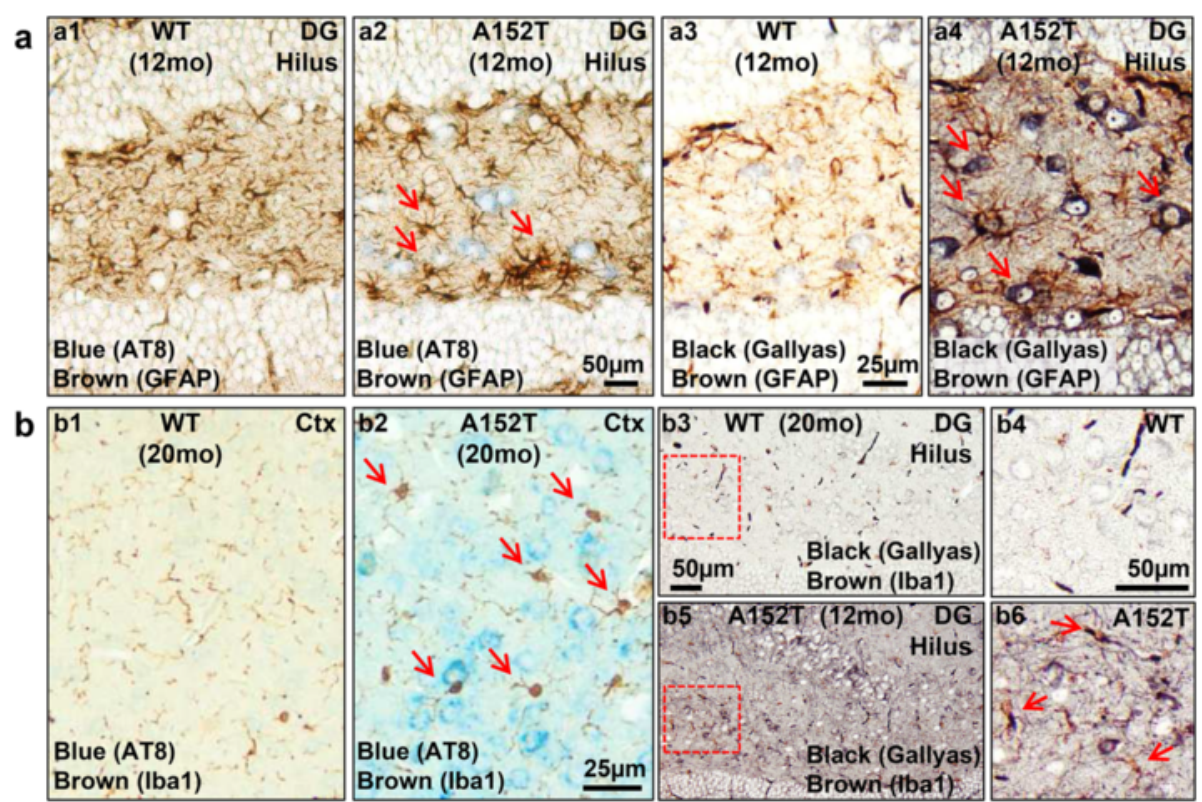

Fig. 7 Inflammation vs. Tau pathology. a-b Paraffin sections of 12 months old hTau40 AT and WT mice were co-stained for neuroinflammation (GFAP or Iba1; brown) and Tau-phosphorylation (AT8; blue) or neuroinflammation (GFAP or Iba1, brown) and Tau-aggregation (Gallyas silver; black). Note the accumulation of glial cells in the surrounding of hippocampal neurons bearing pathological, AT8-phosphorylated Tau (a2 and b2, arrows) or NFTs (a4 and b5-6, arrows) in hTau40 AT mice. Age-matched controls show no AT8-staining, no NFTs and only a few astrocytes and microglia (a1, a3, b1, b3-4). Red-boxed areas $(\mathrm{b3}, \mathrm{b5})$ indicate close-ups (b4, b6). WT: wildtype; A152T: hTau40 ${ }^{\mathrm{AT}}$ transgenic mouse strain; CA: cornu ammonis; Ctx: cortex; DG: dentate gyrus; mo: months; Scale bar: 25 mm (a3-4, b1-2), 50 m (a1-2, b3-6) 


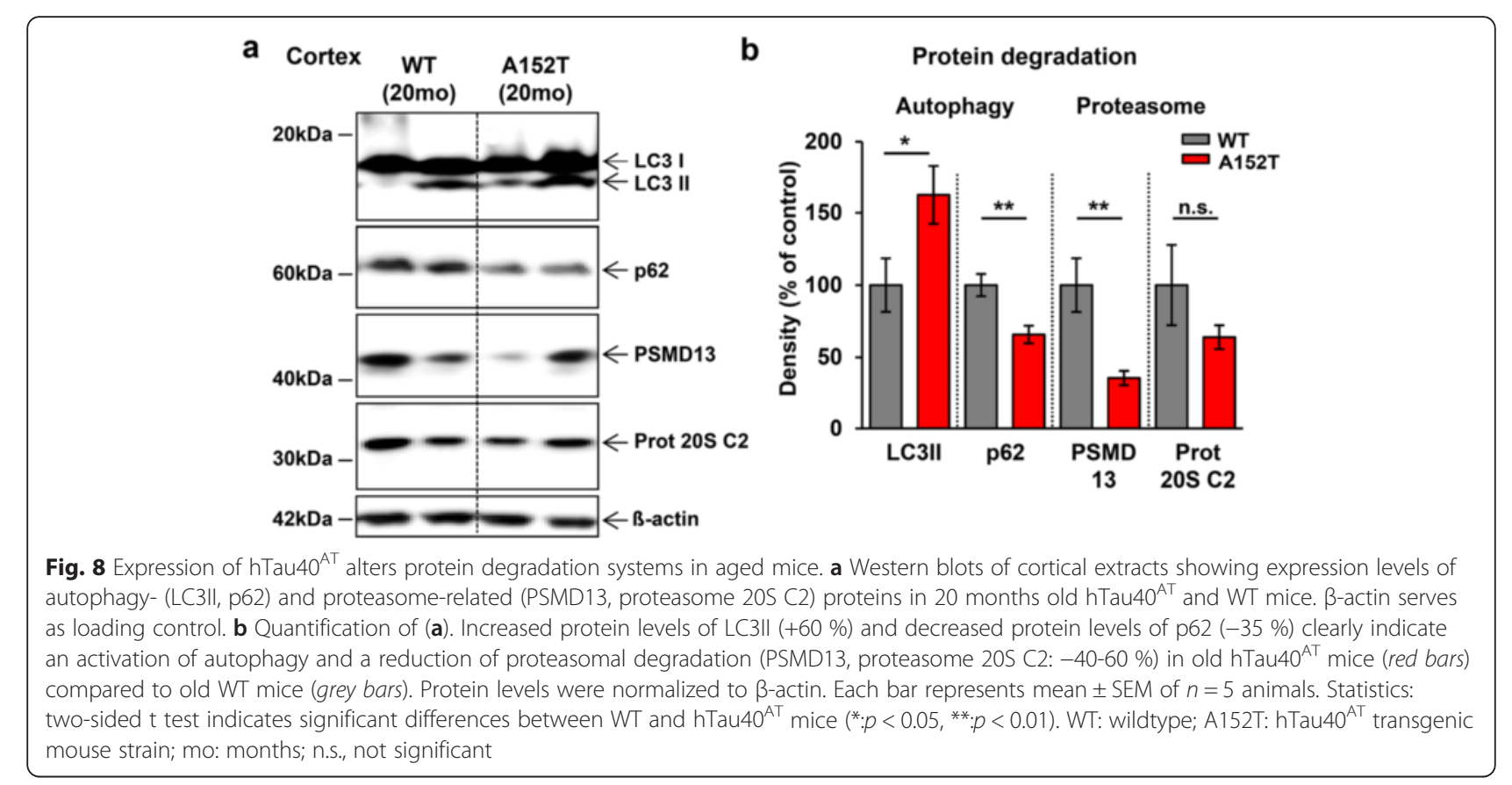

The cognitive performance of hTau $40^{\mathrm{AT}}$ mice was investigated using a Morris water maze (MWM) test. Swimming speed did not differ from WT controls at 10 and 16 months of age, confirming normal motor abilities of the animals (Additional file 1: Figure S3). Regarding spatial learning and memory, hTau $40^{\mathrm{AT}}$ mice were indistinguishable from age-matched controls at 10 months of age, demonstrating intact cognitive function at early Tau pathological stages (Fig. 10a, b). However, at 16 months there was pronounced impairment of spatial learning. In comparison to controls, hTau $40^{\mathrm{AT}}$ mice were considerably slower to reach the hidden platform during MWM acquisition as demonstrated by an increased escape latency and path length (interaction effect genotype $\mathrm{x}$ day for escape latency: $p=0.033, \mathrm{~F}_{(4,116)}=2.72$; interaction effect genotype $\mathrm{x}$ day for path length: $p=0.027, \mathrm{~F}_{(4,116)}=$ 2.88) (Fig. 10c). In addition, probe trials conducted at days $3,4,5$ and 2 days after finishing the acquisition phase (long-term probe trial) revealed severe short- and longterm memory impairments of 16 months old hTau $40^{\mathrm{AT}}$ mice in comparison to WT mice, as indicated by a reduced preference for the target quadrant (Fig. 10d, Additional file 1: Figure S3f).

Taken together, the accumulation of endogenous and exogenous mutant Tau in hTau $40^{\mathrm{AT}}$ mice in the hippocampus correlates with impairment of spatial learning and memory at $\sim 16$ months of age, which parallels the overall increase of brain inflammation, synapse loss and neuronal death. In addition the loss of cognitive function correlates with the loss of synapses and pyramidal neurons in the hippocampus which was initially observed with $\sim 12$ months of age (Fig. 11).

\section{Discussion}

In recent years several Tau mutations have been identified as genetic risk factors for FTDP-17 [36, 48]. Most of the mutations are located in the repeat domain (microtubule binding region; e.g. P301L, P301S and $\Delta$ K280) and reduce the Tau-MT-interaction and MT-assembly and/or increase Tau-aggregation by enhancing the $B$-propensity of Tau. This results in Tau-hyperphosphorylation, missorting and aggregation $[42,109]$. By contrast, mutations in the Nterminal Tau projection domain (i.e. R5L, G55R), which are partly related to PSP [R5L, [86]], and their underlying mechanisms are not well understood at present. However, $\mathrm{N}$-terminal mutations may impact on the 3D-structure of Tau (e.g. the "paperclip conformation", [52]) or influence intra- and intermolecular interactions that might affect MT and neuronal cell functions [51]. The MAPT p.A152T variant was recently recognized as a risk factor for several FTD spectrum disorders including $\mathrm{AD}$, highlighting the clinical and pathological variability associated with MAPT p.A152T $[20,38,55,57,60]$. To address the question of how p.A152T Tau induces neuropathological features including cognitive decline, we generated a novel transgenic mouse model expressing human full-length Tau with mutation A152T (hTau40 ${ }^{\mathrm{AT}}$ ).

\section{Neuropathology of hTau $40^{\mathrm{AT}}$ mice in comparison to AD- and PSP-cases and Tau transgenic mouse models} In spite of the low, near-physiological transgene expression, hTau $40^{\mathrm{AT}}$ causes Tau-hyperphosphorylation at several diagnostic sites (e.g. AT8, PHF1) and Tau-missorting of transgenic and endogenous Tau into the somatodendritic compartment of neurons starting at early age (Figs. 3, 4, 


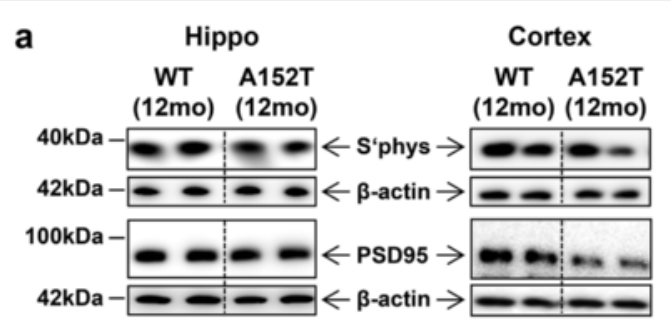

C Golgi-staining - CA1 and CA3 region $(20 \mathrm{mo})$

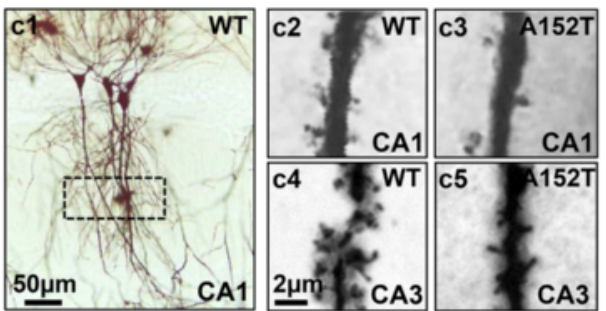

b

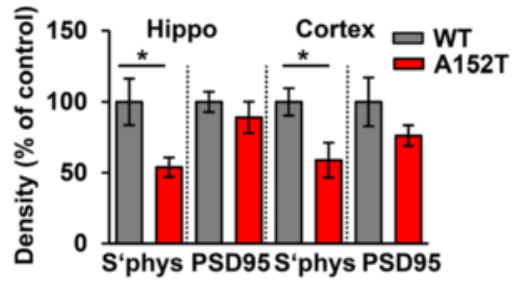

d Spine densities of apical dendrites

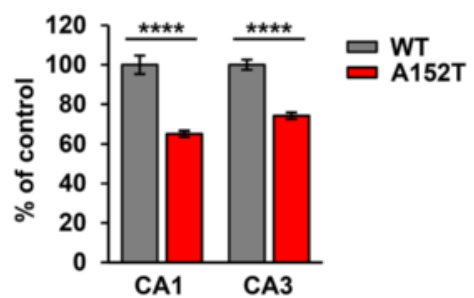

e Fluoro Jade $\mathrm{C}$ staining
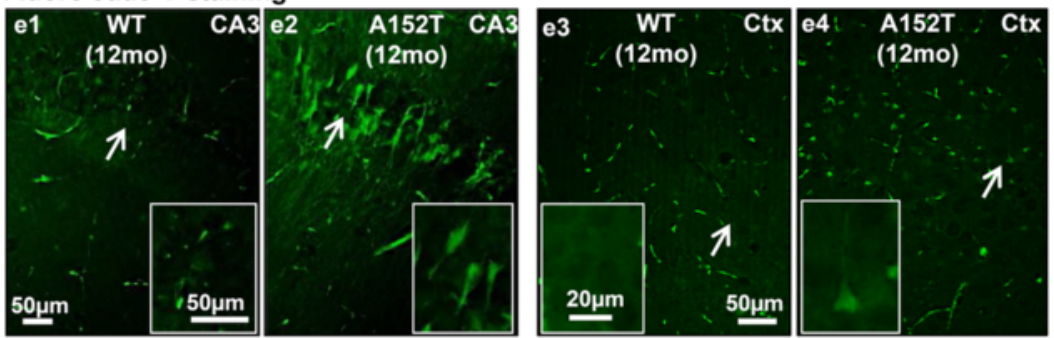

f

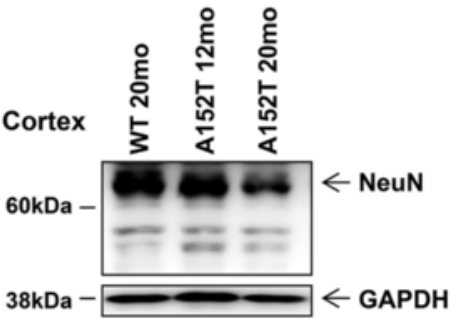

g

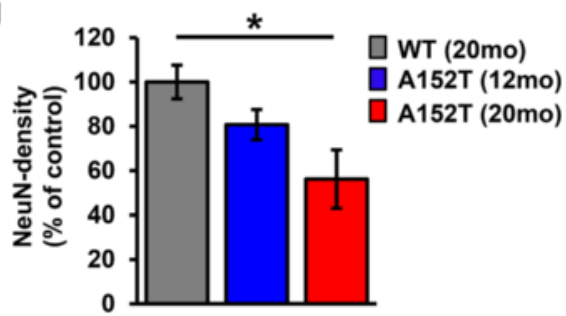

Fig. 9 Synapse loss and neurodegeneration in hTau40 ${ }^{A T}$ mice. a Western blots of hippocampus and cortex extracts showing expression levels of synaptic proteins (synaptophysin and PSD-95) of 12 months old hTau40 AT and WT mice. $\beta$-actin serves as loading control. Decreased levels of pre-synaptic (synaptophysin) and post-synaptic (PSD-95) markers are detected in hTau40 AT mice compared to WT. b Quantification of (a), normalized to B-actin. Red bars indicate a reduction of pre-synaptic (synaptophysin) and postsynaptic (PSD-95) markers in hTau40 ${ }^{\mathrm{AT}}$ mice. Bars show mean \pm SEM; $n=5$. Statistics: two-sided t test indicates significant differences between WT and hTau40 ${ }^{\mathrm{AT}}$ mice $(*: p<0.05)$. c Dendritic spine density analyzed by Golgi-staining. (c1) Overview of Golgi-stained CA1 neurons of WT mouse with highlighted region of interest (box). (c2-c5) Higher magnification of CA1 and CA3 apical dendrites of hTau40 AT mice compared to WT at 20 months of age. Scale bar c1, $50 \mu \mathrm{m} ; \mathrm{c} 2-5,2 \mu$ m. d Quantification of (c). A highly significant reduction of dendritic spines is detected in 20 months old hTau40 ${ }^{\mathrm{AT}}$ mice (red bar, CA1: 35 \%; CA3: 25 \%) compared to WT mice (grey bars). Bars show mean values \pm SEM; $n=2-3$ mice per group. Statistics: two-sided t test, ${ }^{* * *}: p<0.0001$. e Fluoro Jade $C$ staining of floating sections from 12 months old $\mathrm{hTau} 4 \mathrm{O}^{\mathrm{AT}}$ and $\mathrm{WT}$ mice to visualize neurodegenerative processes. Note the intense neurodegeneration in the CA3 region (e2) and cortex of hTau40 ${ }^{\mathrm{AT}}$ mice (e4) compared to WT mice (e1, e3). Arrows in the overviews indicate the location of higher magnified neurons (inserts). f Western blots of cortex extracts show NeuN expression levels in 12 and 20 months old hTau40 ${ }^{\text {AT }}$ and WT mice. GAPDH serves as loading control. Note the dramatic loss of NeuN (especially $\sim 66 \mathrm{kDa}$ ) in 20 months old hTau40 ${ }^{\mathrm{AT}}$ mice compared to 12 months old hTau40 and 20 months old WT mice. $\mathbf{g}$ Quantification of (f), normalized to GAPDH. Red bar indicates neuronal loss of $\sim 40 \%$ in 20 months old hTau40 ${ }^{\text {AT }}$ mice compared to age-matched WT mice. Data represent mean values $\pm \mathrm{SEM} ; n=4$. Statistical comparisons were accomplished by one-way ANOVA followed by a post hoc Newman-Keuls multiple comparison test using Prism 5.0 (GraphPad Software). Asterisk indicates significant difference between WT and 20 months old hTau40 ${ }^{\mathrm{AT}}$ mice $\left(^{*}: p<0.05\right)$. WT: wildtype; A152T: hTau40 ${ }^{\mathrm{AT}}$ transgenic mouse strain; CA: cornu ammonis; Ctx: cortex; mo: months; Scale bars: $2 \mu \mathrm{m}$ (c2-5), $20 \mu \mathrm{m}$ (inserts of e3-4), $50 \mu \mathrm{m}$ (e1-4; inserts of e1-2) 


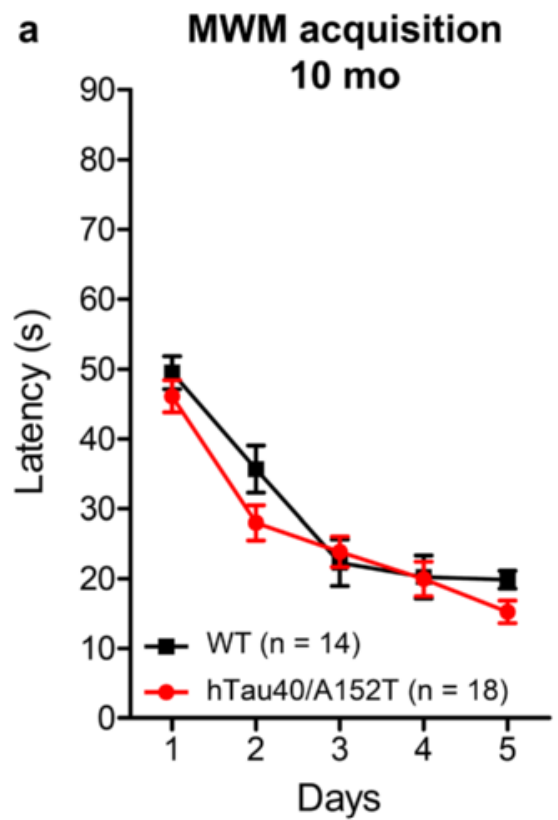

b MWM probe trials $10 \mathrm{mo}$

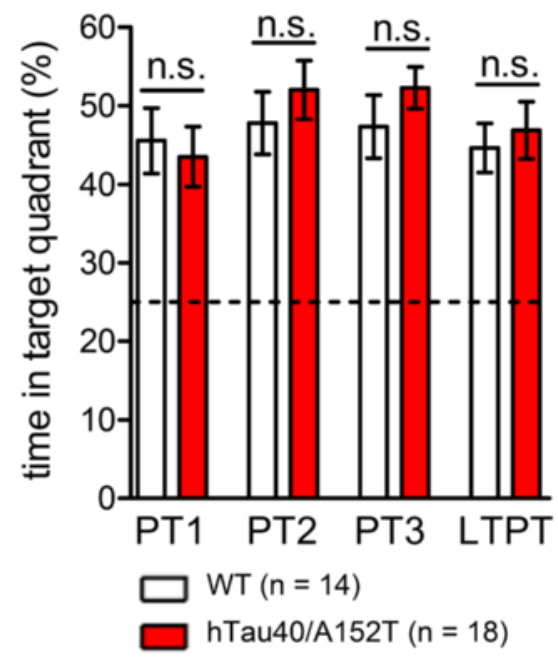

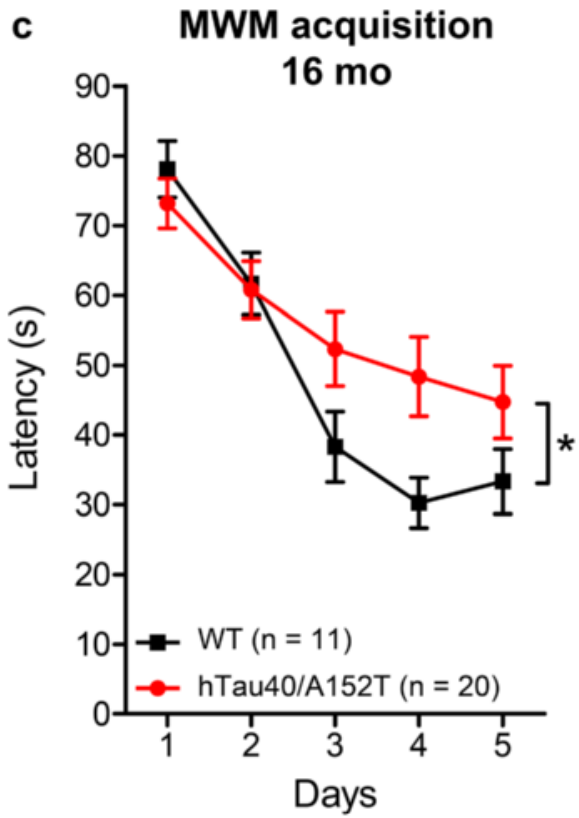

d

MWM probe trials $16 \mathrm{mo}$

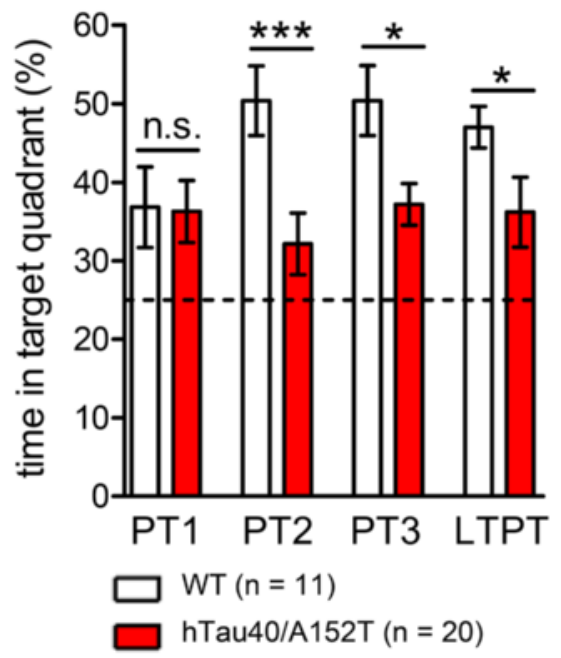

Fig. 10 Cognitive impairment of hTau40 AT mice at 16 months of age. Morris water maze (MWM) test of 10 and 16 months old hTau40 ${ }^{\mathrm{AT}}$ mice in comparison to age-matched WT littermates. $\mathbf{a}$, b At 10 months of age, spatial learning of hTau40 ${ }^{\text {AT }}$ mice during a MWM acquisition is similar to WT controls and (b) hTau $40^{\mathrm{AT}}$ mice show a high preference for the target quadrant $(>40 \%$ ), which is comparable to controls throughout all probe trials, indicating preservation of cognitive functions at 10 months of age. $\mathbf{c}$ In contrast, 16 months old hTau40 ${ }^{\mathrm{AT}}$ mice are impaired in learning the position of the hidden platform as demonstrated by significantly increased escape latencies during MWM acquisition in comparison to control mice (interaction effect, genotype $x$ day, $p=0.033, F_{(4,116)}=2.72$ ). $\mathbf{d}$ Moreover $h T a u 40^{A T}$ mice exhibit a lower preference for the target quadrant than WT animals from probe trial 2 onwards, pointing towards severe short- and long-term memory deficits due to accumulation of hTau40 ${ }^{\mathrm{AT}}$ at advanced age. a, c Data show mean escape latency $(s) \pm$ SEM for 10 months old WT $(n=14)$ vs hTau40 AT mice $(n=18)$ and 16 months old WT $(n=11)$ vs hTau40 AT mice $(n=20)$. Statistics: two-way repeated measure analysis of variances with post hoc Fishers LSD multiple comparisons test. Asterisks indicate a significant effect of interaction (genotype $x$ day) between $h T a u 40^{A T}$ mice and control group, ${ }^{*}: p<0.05$. b, $\mathbf{d}$ Bars represent mean time in target quadrant (\%) \pm SEM for 10 months old WT $(n=14)$ vs hTau40 AT mice $(n=18)$ and 16 months old WT $(n=11)$ vs hTau40 AT mice $(n=20)$. Statistics: two-tailed Students t-test between hTau40 ${ }^{\mathrm{AT}}$ mice and control group for each probe trial, ${ }^{*}: p<0.05,{ }^{* * *}: p<0.001 ;$ n: number of mice; WT: wild-type animals; mo: months of age 


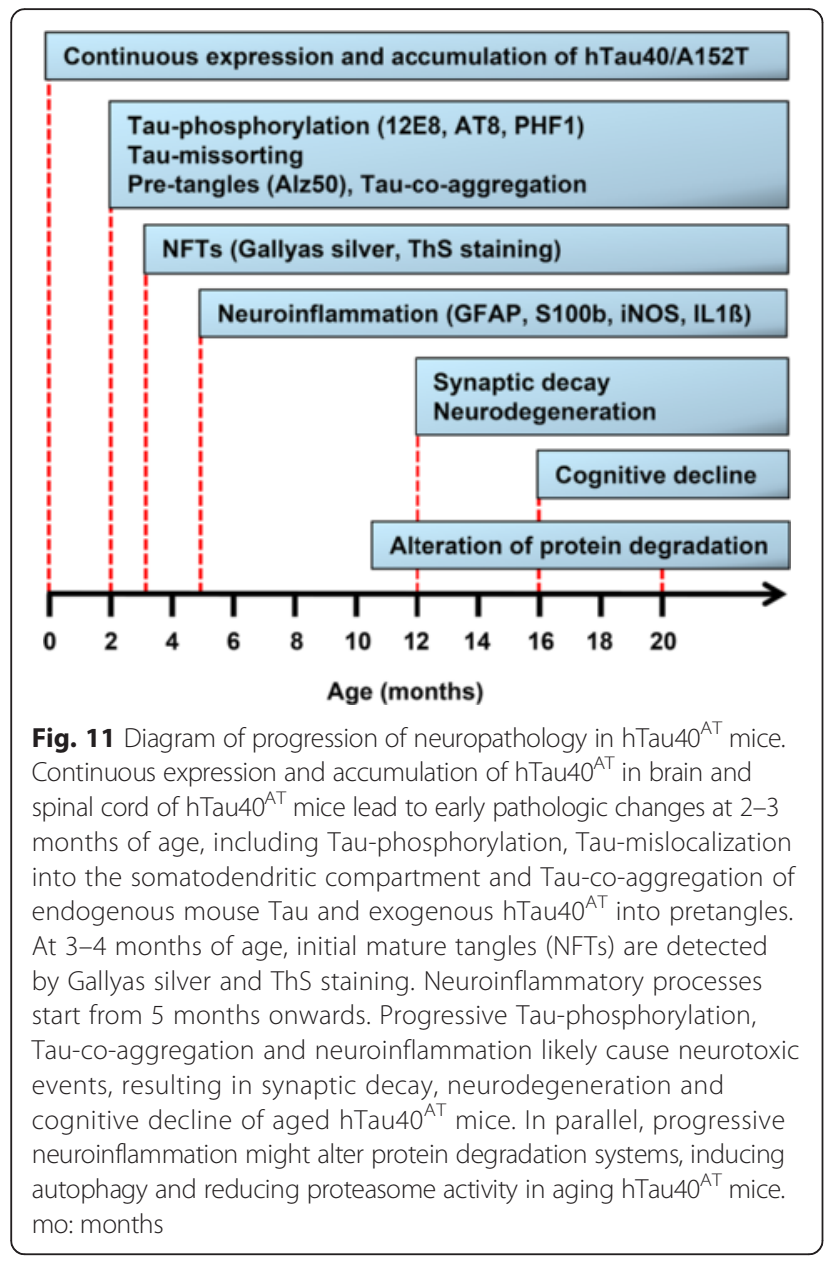

Additional file 1: Figure S1). The results are comparable to tauopathy mouse models with FTDP-17-related Taumutations [30, 62, 75, 87, 92] and to pathological reports of AD- and PSP-cases [16, 76].

Furthermore $M A P T$ p.A152T increases the hydrophilic character of Tau and generates an additional phosphorylation site just upstream of the TP-motif 153-154 [57], which is one of numerous targets in Tau by prolinedirected kinases (i.e. MAPK, cdk5 and GSK3). This type of phosphorylation is characteristically increased in most tauopathies, and indeed, the phosphorylation of T153 is observed both in cell models and AD brain $[5,49]$. Thus the mutation $\mathrm{Ala} \rightarrow \mathrm{Thr}$ in the preceding residue 152 could impact the phosphorylation pattern and function of this region of Tau.

In vitro, hTau $40^{\mathrm{AT}}$ shows a somewhat reduced tendency to form Tau-fibers and an increase in oligomers [20]. However, in mice the exogenous hTau $40^{\mathrm{AT}}$ is able to interact with endogenous mouse Tau to form stable co-aggregates and flame-shape NFTs (Fig. 2), comparable to transgenic mice expressing human Tau variants with mutations in the repeat domain or C-terminus, such as G272V, $\Delta \mathrm{K} 280$, P301S, P301L and R406W [3, 75, 91, 104, 116].
Neuropathologically, Tau-co-aggregates detected in hTau $40^{\mathrm{AT}}$ mice resemble neuronal NFTs of AD-patients rather than the spherical tangles of PSP-patients [13, 17, 105]. Furthermore "tufted astrocytes" containing abnormal Tau deposits, a classical marker of PSP [12], are lacking in mice and in patients with mutated hTau $40^{\mathrm{AT}}$ [57].

Although hTau $40^{\mathrm{AT}}$ mice develop remarkable Tau phosphorylation and aggregation in spinal and motor cortical neurons (Figs. 2 and 3), motor functions were preserved (Additional file 1: Figures S4, S5). This is in contrast to earlier generations of Tau-transgenic mice with high overexpression of mutant Tau in the CNS including spinal cord, which show strong motor deficits and thus interfere with cognitive assays such as MWM and others $[61,62,96,107,116]$. However, the hTau $40^{\mathrm{AT}}$-expression (due to a single copy in the ROSA26-locus) seems to be low enough to avoid motor deficits in hTau $40^{\mathrm{AT}}$ mice and thus to allow cognitive testing, similar to other mouse models with rather near-physiological levels of Tau transgene expression in the spinal cord [82, 92].

From our results we conclude that the expression of A152T-Tau (a Tau-variant mutated in the N-terminal half, near the proline-rich region) leads to hyperphosphorylation, missorting and aggregation of Tau, similar to pathological features of FTDP-mouse models expressing human Tau-variants with mutations in the C-terminal half that are known to affect Tau-microtubule interactions and Tau-aggregation [91, 92, 116]. How this A152T-Tau promotes tauopathy (e.g. by impacting the 3D-structure of Tau, alterations in MT dynamics, phosphorylation pattern, sensitivity to proteases etc.) will require further investigation. But the proximity to the central proline-rich domain which harbors interaction sites with proteins with $\mathrm{SH} 3$ domains [40] is suggestive of a role in altered signaling pathways. In this context it is interesting to note that the trans-cellular spreading of Tau-pathology appears to be mediated by high MW non-fibrillar oligomers of Tau with pronounced hyperphosphorylation by proline-directed kinases [101].

\section{Inflammatory response versus $\mathrm{hTau} 40^{\mathrm{AT}}$-pathology}

Neuroinflammation plays a crucial role in the development and progression of neurodegenerative diseases, but it is still a matter of debate whether inflammatory processes trigger the pathology (e.g. Tau-aggregation) or whether activated glial cells react to the aggregation of toxic proteins in their surrounding [2]. The hTau40 ${ }^{\mathrm{AT}}$ mice develop a remarkable neuroinflammatory response as judged by the activation of astrocytes and microglia and the upregulation of inflammation-related proteins, starting from 5 months onwards (Figs. 5 and 6), similar to reports of patients with chronic neurodegenerative diseases including AD, PSP, PD, ALS and prion disease $[1,31,43,83]$. 
Microglia cells are locally activated by misfolded proteins (e.g. Aß and alpha-synuclein) [83], in particular by structural changes which activate toll-like receptors (TLR) and by expression of pro-inflammatory cytokines (e.g. IL-1ß) or inflammation-induced enzymes like iNOS [28, 45]. Apart from glial cells, neurons can serve as source of cytokines (i.e. IL-1ß), and express inducible nitric oxide synthase (iNOS) in pathological conditions [43, 44], as shown here for CA1-neurons of hTau $40^{\mathrm{AT}}$ mice (Fig. 5).

Similar to the accumulation of activated glial cells in the surrounding of NFT-bearing neurons in hTau $40^{\mathrm{AT}}$ mice (Fig. 7), activated microglia are also associated with $\mathrm{AB}$-plaques in $\mathrm{AD}$ patients and transgenic APP-23 mice [93, 97]. Furthermore, misfolded $\alpha$-synuclein activates directly microglia with a classical cytokine upregulation, morphological changes and alterations in TLR gene expression [11]. Reports on transgenic mice (expressing aggregation-prone Tau variants) strengthen the linkage between the accumulation of intracellular aggregated Tau species and an inflammatory response $[10,75,116]$; whilst the expression of an anti-aggregant Tau variant "protects" mice against a pronounced gliosis [75].

Experiments with implanted IL-1-releasing pellets into rat brains, leading to Tau-hyperphosphorylation, have suggested a function of IL- 1 as trigger for the progression of neurofibrillary pathology in AD [39, 94]. Furthermore, the proinflammatory cytokine TNF initiates the accumulation of Tau preferentially in neurites via reactive oxygen species [37]. Conversely, neuroinflammation and Tau pathology were diminished in PS19 mice by treatment with the anti-inflammatory compound FK506 [116]. Gene expression profiles of $\mathrm{rTg} 4510$ mice suggest a correlation of Tau-pathology, cognitive decline and upregulation of inflammatory genes similar to AD cases [111]. All of these observations point to a tight relationship between Tau toxicity and pro-inflammatory cytokines.

In patients with $\mathrm{AD}$ or PSP, ongoing gliosis is visualized and quantified by positron emission tomography (PET) and usually increases with the disease stage in affected regions [85, 118]. In comparison, in aging bigenic mice (Gfap-luc:hTau40 ${ }^{\mathrm{AT} / \mathrm{m} . \mathrm{bkg}}$ ) the rise of GFAP-dependent luciferase activity reflects the kinetics of astrocyte activation in vivo as monitored by bioluminescence imaging (Fig. 6), confirmed by staining for inflammation markers (Figs. 5 and 6). This underscores the potential of BLI to characterize progressive neurodegenerative diseases (e.g. AD and ALS) [46]. In hTau40 ${ }^{\mathrm{AT}}$ mice the neuroinflammation precedes cognitive decline (Figs. 5, 6, 7, and 10). Based on the probable link between neuroinflammation, Tau-pathology and cognitive failure, BLI of bigenic (Gfap-luc: hTau40 ${ }^{\mathrm{AT} / m i x e d ~ b k g}$ ) mice may be used to validate and improve treatment strategies and define time points of early therapeutic intervention before onset of behavioral deficits.
From our results, we conclude that neuroinflammation in hTau $40^{\mathrm{AT}}$ mice occurs in response to early Tauphosphorylation and Tau-aggregation at young age (Figs. 2 and 3). At later stages, neuroinflammatory changes might further boost Tau pathology and neurotoxic processes, which finally lead to synaptic damage and neuronal death (Figs. 9 and 10).

\section{Accumulation of hTau $40^{\mathrm{AT}}$, neuroinflammation and protein degradation: a reciprocal relationship}

Aberrations in protein clearance systems contribute to the pathogenesis of neurodegeneration, causing the accumulation and aggregation of disease-relevant proteins $[47,59,74,80]$. In the present study, 20 months old hTau $40^{\mathrm{AT}}$ mice show a reduced proteasome activity and an upregulation of the autophagosome-lysosome pathway (Fig. 8), pointing towards a cross-talk between both protein degradation pathways, as suggested by others [56]. In this regard, provoked proteasome impairments (by drugs or gene silencing) induce autophagy as a compensatory protein degradation pathway in various cell models [26, 65, 81]. Similar changes occur after lipopolysaccharide (LPS)-induced neuroinflammation, which decreases proteasome activity and causes hippocampal neurodegeneration [84]. Moreover, autophagy can be upregulated by immune signaling molecules (e.g. TLRs) or the IL1R pathway $[95,98]$. Therefore, the observed changes in the protein degradation systems in the aged $\mathrm{hTau} 40^{\mathrm{AT}}$ mice are likely explained by the progressive neuroinflammation (Figs. 5, 6, 7 and 8).

Conversely, the activation of autophagy would appear as a promising strategy against neurodegeneration, since aggregated proteins (e.g. Tau) are preferentially degraded by chaperone-mediated autophagy [110]. Furthermore, application of autophagy inducers (e.g. rapamycin, trehalose) lowers Tau-hyperphosphorylation and neuroinflammation and improves cognition in transgenic mouse models [29, 68, 89]. Beyond that, trehalose suppresses Tau-aggregation in an inducible N2a cell model of Tau pathology and diminishes cytotoxicity [58]. However, the activation of autophagy in hTau $40^{\mathrm{AT}}$ mice occurs only after NFT formation and onset of neuronal loss, obviously too late to rescue Tau induced toxicity and cognitive phenotype (Figs. 2, 8, 9 and 10), similar to old 3xTg-AD mice with NFTs showing no cognitive recovery after autophagy-activation [69].

\section{Synaptic decay and neuronal loss parallel cognitive impairments in $\mathrm{hTau} 40^{\mathrm{AT}}$ mice}

Synapse loss is a fundamental correlate of cognitive decline in $\mathrm{AD}$ [106]. Our data indicate an age-dependent failure of learning and memory capacities in hTau $40^{\mathrm{AT}}$ mice. At 10 months, when dendritic spine densities are still unaffected, hTau $40^{\mathrm{AT}}$ mice are still cognitively 
normal (Additional file 1: Figure S2; Fig. 10). However, 12 months old hTau $40^{\mathrm{AT}}$ mice show already incipient "synaptotoxicity" observed by reduced levels of synaptic proteins (especially presynaptic markers). Decreased level of synaptophysin (Fig. 9a-b), presumably caused by the accumulation of toxic hTau $40^{\mathrm{AT}}$ inside presynaptic termini, might serve as a first indicator for pathological changes in the synaptic connectivity, as described for other Tau transgenic mice $[75,108,116]$. From 12 months onwards progressive neurodegeneration (Fig. 9e) destroys cognitive pathways, resulting in severe learning and memory deficits of 16 months old hTau $40^{\mathrm{AT}}$ mice (Fig. 10c-d). Consistent with this, cognitively impaired $\sim 20$ months old hTau $40^{\mathrm{AT}}$ mice show a profound loss of CA1- and CA3-synaptic spines (Fig. 9c-d), similar to other tauopathy mouse models, where synapse loss was correlated to cognitive decline $[87,92,100,108]$.

\section{Toxic gain and loss of function in hTau $40^{\mathrm{AT}}$ mice affects cognition}

The mechanisms leading to Tau-dependent neurotoxicity in AD- or FTDP-17-patients remain unclear in detail, but there is evidence that a combination of toxic gain of function and the loss of normal Tau function serves as a trigger for neurodegenerative processes [112]. Under physiological conditions non-mutated Tau stabilizes MTs in axons, but post-translational modifications (e.g. phosphorylation) could alter its interaction with MTs and other cell components and thus might result in impairment of axonal transport, Tau-missorting and formation of PHFs [70]. By contrast, hTau $40^{\mathrm{AT}}$ shows a reduced MT affinity and slower aggregation in vitro, but exhibits an enhanced tendency to form Tau oligomers [20]. Whether the MAPT p.A152T mutation alters the function of the Tau projection domain as MT-spacer [19] or its interaction with the dynactin complex [67], histone deacetylase 6 [24], tyrosine kinases such as Fyn [50] or other proteins is still unknown. Further intramolecular changes of hTau $40^{\mathrm{AT}}$ impacting the 3D-structure cannot be excluded. Since transgenic mice, expressing aggregation-prone Tau proteins, develop early cognitive decline $[87,92,100]$, the co-aggregates of hTau $40^{\mathrm{AT}}$ mice (Fig. 2) might have less beta structure and might be less neurotoxic, postponing memory loss in hTau $40^{\mathrm{AT}}$ mice to older age (Fig. 10).

A proper function of the ubiquitin-proteasome system (UPS) is essential for correct synaptic transmission, since the UPS operates in the pre- and postsynaptic compartment by regulating neurotransmitter release, synaptic vesicle recycling and the dynamic behavior of the PSD and dendritic spines [114]. Proteasome inhibition causes impairment of neuronal protein synthesis [25], loss of synaptic proteins [7] and LTP impairments [27]. Furthermore bilateral hippocampal injection of lactacystin (proteasome inhibitor) produces retrograde amnesia in rats
[64]. In this context, reduced proteasome activity in old hTau $40^{\mathrm{AT}}$ mice (Fig. 8) might impact on synaptic function and trigger synapse loss (Fig. 9) and cognitive decline (Fig. 10).

Neuroinflammatory processes interfere with learning and memory and are related to synaptic decay and neuronal loss in neurodegenerative disorders $[66,115]$. Although physiological levels of IL- $1 ß$ are beneficial for synaptic plasticity [6], IL-1ß-treatments of cultured neurons induced a marked loss of synaptic connections [73]. In astrocytes, elevated levels of IL-1 trigger the overexpression of the neurotrophic cytokine S100b, a calcium binding protein. S100b increases the free calcium concentration in neurons; whereas mice overexpressing S100b show enhanced excitotoxicity, altered synaptic plasticity and cognitive impairment $[9,34,78]$. Since neuroinflammation is a major hallmark of hTau $40^{\mathrm{AT}}$ mice (Figs. 5, 6 and 7), the presence of activated glial cells and inflammatory proteins might serve as major trigger for cognitive decline.

\section{Conclusions}

In summary, the present study shows that expression of $\mathrm{hTau} 40^{\mathrm{AT}}$ at low near-physiological levels is sufficient to induce a severe neuropathology leading to functional deficits and neuronal death in vivo (Fig. 11). Our results support the hypothesis that the rare MAPT p.A152T mutation promotes a neurotoxic gain of function, most likely triggered by the enhanced neuroinflammation and excitotoxic events. Thus the new hTau $40^{\mathrm{AT}}$ mouse model is suitable for further mechanistic studies of Tau induced neurotoxicity and for in vivo validation of compounds covering Tau-pathology and neuroinflammation.

\section{Additional file}

Additional file 1: Supplemental material and results. (PDF $5946 \mathrm{~kb}$ )

\section{Abbreviations}

AB: Amyloid-beta; AD: Alzheimer disease; ALS: Amyotrophic lateral sclerosis; Bkg: background; BLI: bioluminescence imaging; bvFTD: behavioral variant of frontotemporal dementia; CA: cornu ammonis; CBD: corticobasal degeneration; CNS: central nervous system; $\Delta K 280$ : Tau mutant with deletion of lysine 280; DG: dentate gyrus; ES: embryonic stem cells; FTD: frontotemporal dementia; FTDP-17: frontotemporal dementia and parkinsonism linked to chromosome 17; FTD-s: frontotemporal dementia spectrum disorders; GAPDH: Glyceraldehyde 3-phosphate dehydrogenase; GFAP: glial fibrillary acidic protein; HD: Huntington Disease; HSC70: heat shock cognate protein 70; hTau40: human full-length Tau (2N4R, 441 residues); hTau40 AT: hTau40 with mutation A152T; iNOS: inducible nitric oxide synthase; LC3: microtubule-associated protein 1 light chain 3; mf: mossy fibers; mo: months; MT: microtubule; MWM: Morris water maze; NeuN: neuronal nuclear antigen; NFT: neurofibrillary tangle; NMDAR: N-methyl D-aspartate receptor; PET: positron emission tomography, PHF, paired helical filament; Prot 20S C2: C2 subunit of the 20S proteasome; PrP: prion protein; PSD95: postsynaptic density protein 95; PSMD13: a regulatory subunit of the $26 S$ proteasome; PSP: Progressive Supranuclear Palsy SSCtx, somatosensory cortex; $\operatorname{Tau}^{\Delta \mathrm{K}}$ : full-length human Tau (2N4R, residues 1-441) with $\Delta \mathrm{K} 280$ deletion mutation; TauRD ${ }^{\Delta \mathrm{K}}$ : Tau 4-repeat domain (construct K18, residues 244-372) with $\Delta$ K280 mutation; hTau40 ${ }^{\text {AT }}$ : full-length human Tau (2N4R, 
residues 1-441) with A152T mutation; Tg: transgenic; UPS: ubiquitin-proteasome system; WT: wild type; 3D: three dimensional.

\section{Competing interests}

The authors declare that they have no competing interests.

\section{Authors' contributions}

$\mathrm{AS}$ and $\mathrm{KH}$ designed and performed experiments, analyzed data and wrote the manuscript. SK performed behavior and bioluminescence experiments. DC, DM and OP carried out immunoblot and immunohistochemistry analysis. MJ and FJD quantified spine densities. E-MM designed the study and wrote the manuscript. All authors read and approved the final manuscript.

\section{Acknowledgments}

We thank the following lab members for their expert help and advice: Dr. Jacek Biernat (DZNE, Bonn) and S. Hübschmann (DZNE, Bonn) for providing cDNA to generate hTau40 AT mice; Dr. Yipeng Wang (DZNE, Bonn) for fruitful discussions; Stina Hahn (MPI, Hamburg) and Daniel Küver (MPI, Hamburg) for their excellent technical assistance. We owe special thanks to the team of the animal facility of CAESAR (headed by Dr. Dagmar Wachten) and of DZNE Bonn (headed by Dr. Christina Ginkel \& Dr. Michaela Möhring) for their continuous help in mouse breeding. We gratefully acknowledge reagents from Dr. P. Seubert (Elan Pharma, South San Francisco, CA; 12 E8 antibody) and Dr. P. Davies, Albert Einstein College of Medicine, NY (PHF1 and Alz-50 antibodies). This research was supported by MPG, DZNE, Tau Consortium, and Katharina-Hardt-Foundation.

\section{Author details}

${ }^{1}$ German Center for Neurodegenerative Diseases (DZNE), Ludwig-Erhard-Allee 2, 53175 Bonn, Germany. ${ }^{2}$ Max-Planck-Institute for Metabolism Research, Hamburg Outstation, c/o DESY, Notkestrasse 85, 22607 Hamburg, Germany. ${ }^{3}$ CAESAR Research Center, Ludwig-Erhard-Allee 2, 53175 Bonn, Germany.

\section{Received: 23 January 2016 Accepted: 23 January 2016} Published online: 25 February 2016

\section{References}

1. Akiyama H, Barger S, Barnum S, Bradt B, Bauer J, Cole GM, et al. Inflammation and Alzheimer's disease. Neurobiol Aging. 2000;21:383-421.

2. Amor S, Peferoen LA, Vogel DY, Breur M, van der Valk P, Baker D, et al. Inflammation in neurodegenerative diseases-an update. Immunology. 2014; 142:151-66. doi:10.1111/imm.12233.

3. Ando K, Leroy K, Heraud C, Yilmaz Z, Authelet M, Suain V, et al. Accelerated human mutant tau aggregation by knocking out murine tau in a transgenic mouse model. Am J Pathol. 2011;178:803-16. doi:10.1016/j.ajpath.2010.10.034.

4. Andreadis A, Brown WM, Kosik KS. Structure and novel exons of the human tau gene. Biochemistry. 1992;31:10626-33.

5. Augustinack JC, Schneider A, Mandelkow EM, Hyman BT. Specific tau phosphorylation sites correlate with severity of neuronal cytopathology in Alzheimer's disease. Acta Neuropathol. 2002:103:26-35.

6. Avital A, Goshen I, Kamsler A, Segal M, Iverfeldt K, Richter-Levin G, et al. Impaired interleukin-1 signaling is associated with deficits in hippocampal memory processes and neural plasticity. Hippocampus. 2003;13:826-34. doi:10.1002/hipo.10135.

7. Bajic N, Jenner P, Ballard CG, Francis PT. Proteasome inhibition leads to early loss of synaptic proteins in neuronal culture. J Neural Transm. 2012;119: 1467-76. doi:10.1007/s00702-012-0816-9.

8. Baker M, Litvan I, Houlden H, Adamson J, Dickson D, Perez-Tur J, et al. Association of an extended haplotype in the tau gene with progressive supranuclear palsy. Hum Mol Genet. 1999;8:711-5.

9. Barger SW, Van Eldik LJ. S100 beta stimulates calcium fluxes in glial and neuronal cells. J Biol Chem. 1992;267:9689-94.

10. Bellucci A, Westwood AJ, Ingram E, Casamenti F, Goedert M, Spillantini MG. Induction of inflammatory mediators and microglial activation in mice transgenic for mutant human P301S tau protein. Am J Pathol. 2004;165:1643-52. doi:10.1016/S0002-9440(10)63421-9.

11. Beraud D, Maguire-Zeiss KA. Misfolded alpha-synuclein and Toll-like receptors: therapeutic targets for Parkinson's disease. Parkinsonism Relat Disord. 2012;18 Suppl 1:S17-20. doi:10.1016/\$1353-8020(11)70008-6.
12. Bergeron C, Pollanen MS, Weyer L, Lang AE. Cortical degeneration in progressive supranuclear palsy. A comparison with cortical-basal ganglionic degeneration. J Neuropathol Exp Neurol. 1997;56:726-34.

13. Binder LI, Guillozet-Bongaarts AL, Garcia-Sierra F, Berry RW. Tau, tangles, and Alzheimer's disease. Biochim Biophys Acta. 1739;2005:216-23. doi:10.1016/j.bbadis.2004.08.014.

14. Bouabe $\mathrm{H}$, Okkenhaug K. Gene targeting in mice: a review. Methods Mol Biol. 2013;1064:315-36. doi:10.1007/978-1-62703-601-6_23.

15. Braak H, Braak E. Neuropathological stageing of Alzheimer-related changes. Acta Neuropathol. 1991;82:239-59.

16. Buee L, Bussiere T, Buee-Scherrer V, Delacourte A, Hof PR. Tau protein isoforms, phosphorylation and role in neurodegenerative disorders. Brain Res Brain Res Rev. 2000;33:95-130.

17. Bugiani O, Mancardi GL, Brusa A, Ederli A. The fine structure of subcortical neurofibrillary tangles in progressive supranuclear palsy. Acta Neuropathol. 1979;45:147-52.

18. Caroni P. Overexpression of growth-associated proteins in the neurons of adult transgenic mice. J Neurosci Methods. 1997;71:3-9.

19. Chen J, Kanai Y, Cowan NJ, Hirokawa N. Projection domains of MAP2 and tau determine spacings between microtubules in dendrites and axons. Nature. 1992:360:674-7. doi:10.1038/360674a0.

20. Coppola G, Chinnathambi S, Lee JJ, Dombroski BA, Baker MC, Soto-Ortolaza $\mathrm{Al}$, et al. Evidence for a role of the rare p.A152T variant in MAPT in increasing the risk for FTD-spectrum and Alzheimer's diseases. Hum Mol Genet. 2012;21:3500-12. doi:10.1093/hmg/dds161.

21. Cuervo AM, Wong E. Chaperone-mediated autophagy: roles in disease and aging. Cell Res. 2014;24:92-104. doi:10.1038/cr.2013.153.

22. de Calignon A, Polydoro M, Suarez-Calvet M, William C, Adamowicz DH, Kopeikina KJ, et al. Propagation of tau pathology in a model of early Alzheimer's disease. Neuron. 2012;73:685-97. doi:10.1016/j.neuron.2011.11.033.

23. Dickson DW, Kouri N, Murray ME, Josephs KA. Neuropathology of frontotemporal lobar degeneration-tau (FTLD-tau). J Mol Neurosci. 2011;45:384-9. doi:10.1007/s12031-011-9589-0.

24. Ding H, Dolan PJ, Johnson GV. Histone deacetylase 6 interacts with the microtubule-associated protein tau. J Neurochem. 2008;106:2119-30. doi:10.1111/j.1471-4159.2008.05564.x.

25. Ding Q, Dimayuga E, Markesbery WR, Keller JN. Proteasome inhibition induces reversible impairments in protein synthesis. FASEB J. 2006;20:1055-63. doi:10.1096/fj.05-5495com.

26. Ding WX, Ni HM, Gao W, Yoshimori T, Stolz DB, Ron D, et al. Linking of autophagy to ubiquitin-proteasome system is important for the regulation of endoplasmic reticulum stress and cell viability. Am J Pathol. 2007;171:513-24. doi:10.2353/ajpath.2007.070188.

27. Dong C, Upadhya SC, Ding L, Smith TK, Hegde AN. Proteasome inhibition enhances the induction and impairs the maintenance of late-phase longterm potentiation. Learn Mem. 2008;15:335-47. doi:10.1101/Im.984508.

28. Doorn KJ, Moors T, Drukarch B, van de Berg W, Lucassen PJ, van Dam AM Microglial phenotypes and toll-like receptor 2 in the substantia nigra and hippocampus of incidental Lewy body disease cases and Parkinson's disease patients. Acta Neuropathol Commun. 2014;2:90. doi:10.1186/s40478-014-0090-1.

29. Du J, Liang $Y, X u$ F, Sun B, Wang Z. Trehalose rescues Alzheimer's disease phenotypes in APP/PS1 transgenic mice. J Pharm Pharmacol. 2013;65:1753-6. doi:10.1111/jphp.12108.

30. Eckermann K, Mocanu MM, Khlistunova I, Biernat J, Nissen A, Hofmann A, et al. The beta-propensity of Tau determines aggregation and synaptic loss in inducible mouse models of tauopathy. J Biol Chem. 2007;282:31755-65. doi:10.1074/jbc.M705282200.

31. Fernandez-Botran R, Ahmed Z, Crespo FA, Gatenbee C, Gonzalez J, Dickson DW, et al. Cytokine expression and microglial activation in progressive supranuclear palsy. Parkinsonism Relat Disord. 2011;17:683-8. doi:10.1016/j.parkreldis.2011.06.007.

32. Fong $\mathrm{H}$, Wang $\mathrm{C}$, Knoferle J, Walker D, Balestra ME, Tong LM, et al. Genetic correction of tauopathy phenotypes in neurons derived from human induced pluripotent stem cells. Stem Cell Rep. 2013;1:226-34. doi:10.1016/j.stemcr.2013.08.001.

33. Friedrich $G$, Soriano P. Promoter traps in embryonic stem cells: a genetic screen to identify and mutate developmental genes in mice. Genes Dev. 1991:5:1513-23.

34. Gerlai R, Wojtowicz JM, Marks A, Roder J. Overexpression of a calciumbinding protein, $\mathrm{S} 100$ beta, in astrocytes alters synaptic plasticity and impairs spatial learning in transgenic mice. Learn Mem. 1995;2:26-39. 
35. Glaser EM, Van der Loos H. Analysis of thick brain sections by obverse-reverse computer microscopy: application of a new, high clarity Golgi-Nissl stain. J Neurosci Methods. 1981;4:117-25.

36. Goedert M, Jakes R. Mutations causing neurodegenerative tauopathies. Biochim Biophys Acta. 1739;2005:240-50. doi:10.1016/j.bbadis.2004.08.007.

37. Gorlovoy P, Larionov S, Pham TT, Neumann H. Accumulation of tau induced in neurites by microglial proinflammatory mediators. FASEB J. 2009;23:2502-13. doi:10.1096/fj.08-123877.

38. Graff-Radford J, Whitwell JL, Dickson DW, Josephs KA. Pallidonigroluysian atrophy associated with p.A152T variant in MAPT. Parkinsonism Relat Disord. 2013;19:838-41. doi:10.1016/j.parkreldis.2013.04.023.

39. Griffin WS, Sheng JG, Royston MC, Gentleman SM, McKenzie JE, Graham DI, et al. Glial-neuronal interactions in Alzheimer's disease: the potential role of a 'cytokine cycle' in disease progression. Brain Pathol. 1998;8:65-72

40. Hanger DP, Anderton BH, Noble W. Tau phosphorylation: the therapeutic challenge for neurodegenerative disease. Trends Mol Med. 2009;15:112-9. doi:10.1016/j.molmed.2009.01.003.

41. Harris JA, Koyama A, Maeda S, Ho K, Devidze N, Dubal DB, et al. Human P301L-mutant tau expression in mouse entorhinal-hippocampal network causes tau aggregation and presynaptic pathology but no cognitive deficits. PLoS One. 2012;7, e45881. doi:10.1371/journal.pone.0045881.

42. Hasegawa M, Smith MJ, Goedert M. Tau proteins with FTDP-17 mutations have a reduced ability to promote microtubule assembly. FEBS Lett. 1998:437:207-10.

43. Heneka MT, O'Banion MK. Inflammatory processes in Alzheimer's disease. J Neuroimmunol. 2007;184:69-91. doi:10.1016/j.jneuroim.2006.11.017.

44. Heneka MT, Wiesinger H, Dumitrescu-Ozimek L, Riederer P, Feinstein DL, Klockgether T. Neuronal and glial coexpression of argininosuccinate synthetase and inducible nitric oxide synthase in Alzheimer disease. J Neuropathol Exp Neurol. 2001;60:906-16.

45. Hirsch EC, Hunot S. Neuroinflammation in Parkinson's disease: a target for neuroprotection? Lancet Neurol. 2009:8:382-97. doi:10.1016/S14744422(09)70062-6.

46. Hochgräfe K, Mandelkow EM. Making the brain glow: in vivo bioluminescence imaging to study neurodegeneration. Mol Neurobiol. 2013;47:868-82. doi:10.1007/s12035-012-8379-1.

47. Huang Q, Figueiredo-Pereira ME. Ubiquitin/proteasome pathway impairment in neurodegeneration: therapeutic implications. Apoptosis. 2010;15:1292-311. doi:10.1007/s10495-010-0466-z.

48. Hutton M, Lendon CL, Rizzu P, Baker M, Froelich S, Houlden $H$, et al. Association of missense and 5'-splice-site mutations in tau with the inherited dementia FTDP-17. Nature. 1998;393:702-5. doi:10.1038/31508.

49. Illenberger S, Zheng-Fischhofer Q, Preuss U, Stamer K, Baumann K, Trinczek $B$, et al. The endogenous and cell cycle-dependent phosphorylation of tau protein in living cells: implications for Alzheimer's disease. Mol Biol Cell. 1998;9:1495-512.

50. Ittner LM, Ke YD, Delerue F, Bi M, Gladbach A, van Eersel J, et al. Dendritic function of tau mediates amyloid-beta toxicity in Alzheimer's disease mouse models. Cell. 2010;142:387-97. doi:10.1016/j.cell.2010.06.036.

51. Iyer A, Lapointe NE, Zielke K, Berdynski M, Guzman E, Barczak A, et al. A novel MAPT mutation, G55R, in a frontotemporal dementia patient leads to altered Tau function. PLoS One. 2013;8, e76409. doi:10.1371/journal. pone.0076409.

52. Jeganathan $S$, von Bergen M, Brutlach $H$, Steinhoff HJ, Mandelkow E. Global hairpin folding of tau in solution. Biochemistry. 2006;45:2283-93. doi:10. 1021/bi0521543.

53. Jicha GA, Berenfeld B, Davies P. Sequence requirements for formation of conformational variants of tau similar to those found in Alzheimer's disease. J Neurosci Res. 1999;55:713-23.

54. Josephs KA, Hodges JR, Snowden JS, Mackenzie IR, Neumann M, Mann DM, et al. Neuropathological background of phenotypical variability in frontotemporal dementia. Acta Neuropathol. 2011;122:137-53. doi:10.1007/s00401-011-0839-6.

55. Kara E, Ling H, Pittman AM, Shaw K, de Silva R, Simone R, et al. The MAPT p. A152T variant is a risk factor associated with tauopathies with atypical clinical and neuropathological features. Neurobiol Aging. 2012;33:2231 e2237-14. doi:10.1016/j.neurobiolaging.2012.04.006.

56. Korolchuk VI, Menzies FM, Rubinsztein DC. Mechanisms of cross-talk between the ubiquitin-proteasome and autophagy-lysosome systems. FEBS Lett. 2010;584:1393-8. doi:10.1016/j.febslet.2009.12.047.
57. Kovacs GG, Wohrer A, Strobel T, Botond G, Attems J, Budka H. Unclassifiable tauopathy associated with an A152T variation in MAPT exon 7. Clin Neuropathol. 2011;30:3-10.

58. Krüger U, Wang Y, Kumar S, Mandelkow EM. Autophagic degradation of tau in primary neurons and its enhancement by trehalose. Neurobiol Aging. 2012;33:2291-305. doi:10.1016/j.neurobiolaging.2011.11.009.

59. Lee MJ, Lee JH, Rubinsztein DC. Tau degradation: the ubiquitin-proteasome system versus the autophagy-lysosome system. Prog Neurobiol. 2013;105:49-59. doi:10.1016/j.pneurobio.2013.03.001.

60. Lee SE, Tartaglia MC, Yener G, Genc S, Seeley WW, Sanchez-Juan P, et al. Neurodegenerative disease phenotypes in carriers of MAPT p. A152T, a risk factor for frontotemporal dementia spectrum disorders and Alzheimer disease. Alzheimer Dis Assoc Disord. 2013;27:302-9. doi:10.1097/WAD. Ob013e31828cc357.

61. Leroy K, Bretteville A, Schindowski K, Gilissen E, Authelet M, De Decker $\mathrm{R}$, et al. Early axonopathy preceding neurofibrillary tangles in mutant tau transgenic mice. Am J Pathol. 2007;171:976-92. doi:10.2353/ajpath. 2007.070345.

62. Lewis J, McGowan E, Rockwood J, Melrose H, Nacharaju P, Van Slegtenhorst $M$, et al. Neurofibrillary tangles, amyotrophy and progressive motor disturbance in mice expressing mutant (P301L) tau protein. Nat Genet. 2000;25:402-5. doi:10.1038/78078.

63. Liu L, Drouet V, Wu JW, Witter MP, Small SA, Clelland C, et al. Trans-synaptic spread of tau pathology in vivo. PLoS One. 2012;7, e31302. doi:10.1371/ journal.pone.0031302.

64. Lopez-Salon M, Alonso M, Vianna MR, Viola H, Mello e Souza T, Izquierdo I, et al. The ubiquitin-proteasome cascade is required for mammalian long-term memory formation. Eur J Neurosci. 2001;14:1820-6.

65. Low P, Varga A, Pircs K, Nagy P, Szatmari Z, Sass M, et al. Impaired proteasomal degradation enhances autophagy via hypoxia signaling in Drosophila. BMC Cell Biol. 2013;14:29. doi:10.1186/1471-2121-14-29.

66. Lyman M, Lloyd DG, Ji X, Vizcaychipi MP, Ma D. Neuroinflammation: the role and consequences. Neurosci Res. 2014;79:1-12. doi:10.1016/j.neures.2013.10.004.

67. Magnani E, Fan J, Gasparini L, Golding M, Williams M, Schiavo G, et al. Interaction of tau protein with the dynactin complex. EMBO J. 2007;26:4546-54. doi:10.1038/sj.emboj.7601878.

68. Majumder S, Caccamo A, Medina DX, Benavides AD, Javors MA, Kraig E, et al. Lifelong rapamycin administration ameliorates age-dependent cognitive deficits by reducing $\mathrm{IL}-1$ beta and enhancing NMDA signaling. Aging Cell. 2012;11:326-35. doi:10.1111/j.1474-9726.2011.00791.x.

69. Majumder S, Richardson A, Strong R, Oddo S. Inducing autophagy by rapamycin before, but not after, the formation of plaques and tangles ameliorates cognitive deficits. PLoS One. 2011;6, e25416. doi:10.1371/journal.pone.0025416.

70. Mandelkow EM, Mandelkow E. Biochemistry and cell biology of tau protein in neurofibrillary degeneration. Cold Spring Harb Perspect Med. 2012;2: a006247. doi:10.1101/cshperspect.a006247.

71. Metcalf DJ, Garcia-Arencibia M, Hochfeld WE, Rubinsztein DC. Autophagy and misfolded proteins in neurodegeneration. Exp Neurol. 2012;238:22-8. doi:10.1016/j.expneurol.2010.11.003.

72. Middeldorp J, Hol EM. GFAP in health and disease. Prog Neurobiol. 2011;93:421-43. doi:10.1016/j.pneurobio.2011.01.005.

73. Mishra A, Kim HJ, Shin AH, Thayer SA. Synapse loss induced by interleukin1 beta requires pre- and post-synaptic mechanisms. J Neuroimmune Pharmacol. 2012;7:571-8. doi:10.1007/s11481-012-9342-7.

74. Mittal S, Ganesh S. Protein quality control mechanisms and neurodegenerative disorders: Checks, balances and deadlocks. Neurosci Res. 2010;68:159-66. doi:10.1016/j.neures.2010.08.002.

75. Mocanu MM, Nissen A, Eckermann K, Khlistunova I, Biernat J, Drexler D, et al The potential for beta-structure in the repeat domain of tau protein determines aggregation, synaptic decay, neuronal loss, and coassembly with endogenous Tau in inducible mouse models of tauopathy. J Neurosci. 2008;28:737-48. doi:10.1523/JNEUROSCI.2824-07.2008.

76. Morishima-Kawashima M, Hasegawa M, Takio K, Suzuki M, Yoshida H, Titani $\mathrm{K}$, et al. Proline-directed and non-proline-directed phosphorylation of PHFtau. J Biol Chem. 1995;270:823-9.

77. Morris R. Developments of a water-maze procedure for studying spatial learning in the rat. J Neurosci Methods. 1984;11:47-60.

78. Mrak RE, Griffin WS. Interleukin-1, neuroinflammation, and Alzheimer's disease. Neurobiol Aging. 2001;22:903-8.

79. Neumann M, Tolnay M, Mackenzie IR. The molecular basis of frontotemporal dementia. Expert Rev Mol Med. 2009;11, e23. doi:10.1017/S1462399409001136. 
80. Pan T, Kondo S, Le W, Jankovic J. The role of autophagy-lysosome pathway in neurodegeneration associated with Parkinson's disease. Brain. 2008;131: 1969-78. doi:10.1093/brain/awm318.

81. Pandey UB, Nie Z, Batlevi Y, McCray BA, Ritson GP, Nedelsky NB, et al. HDAC6 rescues neurodegeneration and provides an essential link between autophagy and the UPS. Nature. 2007;447:859-63. doi:10.1038/ nature05853.

82. Pennanen $\mathrm{L}$, Wolfer DP, Nitsch RM, Gotz J. Impaired spatial reference memory and increased exploratory behavior in P301L tau transgenic mice. Genes Brain Behav. 2006;5:369-79. doi:10.1111/j.1601-183X.2005.00165.X.

83. Perry VH, Nicoll JA, Holmes C. Microglia in neurodegenerative disease. Nat Rev Neurol. 2010;6:193-201. doi:10.1038/nrneurol.2010.17.

84. Pintado C, Gavilan MP, Gavilan E, Garcia-Cuervo L, Gutierrez A, Vitorica J, et al. Lipopolysaccharide-induced neuroinflammation leads to the accumulation of ubiquitinated proteins and increases susceptibility to neurodegeneration induced by proteasome inhibition in rat hippocampus. J Neuroinflammation. 2012:9:87. doi:10.1186/1742-2094-9-87.

85. Politis M, Su P, Piccini P. Imaging of microglia in patients with neurodegenerative disorders. Front Pharmacol. 2012;3:96. doi:10.3389/fphar.2012.00096.

86. Poorkaj P, Muma NA, Zhukareva V, Cochran EJ, Shannon KM, Hurtig H, et al. An R5L tau mutation in a subject with a progressive supranuclear palsy phenotype. Ann Neurol. 2002;52:511-6. doi:10.1002/ana.10340.

87. Ramsden M, Kotilinek L, Forster C, Paulson J, McGowan E, SantaCruz K, et al. Age-dependent neurofibrillary tangle formation, neuron loss, and memory impairment in a mouse model of human tauopathy (P301L). J Neurosci. 2005;25:10637-47. doi:10.1523/JNEUROSCI.3279-05.2005.

88. Ricobaraza A, Cuadrado-Tejedor M, Marco S, Perez-Otano I, Garcia-Osta A. Phenylbutyrate rescues dendritic spine loss associated with memory deficits in a mouse model of Alzheimer disease. Hippocampus. 2010. doi:10.1002/hipo.20883

89. Rodriguez-Navarro JA, Rodriguez L, Casarejos MJ, Solano RM, Gomez A, Perucho J, et al. Trehalose ameliorates dopaminergic and tau pathology in parkin deleted/tau overexpressing mice through autophagy activation. Neurobiol Dis. 2010;39:423-38. doi:10.1016/j.nbd.2010.05.014.

90. Rohrer JD, Paviour D, Vandrovcova J, Hodges J, de Silva R, Rossor MN. Novel L284R MAPT mutation in a family with an autosomal dominant progressive supranuclear palsy syndrome. Neurodegener Dis. 2011;8:149-52. doi:10.1159/000319454.

91. Santacruz K, Lewis J, Spires T, Paulson J, Kotilinek L, Ingelsson M, et al. Tau suppression in a neurodegenerative mouse model improves memory function. Science. 2005:309:476-81. doi:10.1126/science.1113694.

92. Schindowski K, Bretteville A, Leroy K, Begard S, Brion JP, Hamdane M, et al. Alzheimer's disease-like tau neuropathology leads to memory deficits and loss of functional synapses in a novel mutated tau transgenic mouse without any motor deficits. Am J Pathol. 2006;169:599-616. doi:10.2353/ajpath.2006.060002.

93. Sheng JG, Ito K, Skinner RD, Mrak RE, Rovnaghi $C R$, Van Eldik $L$, et al. In vivo and in vitro evidence supporting a role for the inflammatory cytokine interleukin-1 as a driving force in Alzheimer pathogenesis. Neurobiol Aging. 1996;17:761-6.

94. Sheng JG, Zhu SG, Jones RA, Griffin WS, Mrak RE. Interleukin-1 promotes expression and phosphorylation of neurofilament and tau proteins in vivo. Exp Neurol. 2000;163:388-91. doi:10.1006/exnr.2000.7393.

95. Shi CS, Kehrl JH. TRAF6 and A20 regulate lysine 63-linked ubiquitination of Beclin-1 to control TLR4-induced autophagy. Sci Signal. 2010;3:ra42. doi:10.1126/scisignal.2000751.

96. Spittaels K, Van den Haute C, Van Dorpe J, Bruynseels K, Vandezande K, Laenen $\mathrm{I}$, et al. Prominent axonopathy in the brain and spinal cord of transgenic mice overexpressing four-repeat human tau protein. Am J Pathol. 1999;155:2153-65. doi:10.1016/S0002-9440(10)65533-2.

97. Stalder M, Phinney A, Probst A, Sommer B, Staufenbiel M, Jucker M. Association of microglia with amyloid plaques in brains of APP23 transgenic mice. Am J Pathol. 1999;154:1673-84. doi:10.1016/S0002-9440(10)65423-5.

98. Sumpter Jr R, Levine B. Autophagy and innate immunity: triggering, targeting and tuning. Semin Cell Dev Biol. 2010;21:699-711. doi:10.1016/j. semcdb.2010.04.003.

99. Sun A, Nguyen XV, Bing G. Comparative analysis of an improved thioflavin-s stain, Gallyas silver stain, and immunohistochemistry for neurofibrillary tangle demonstration on the same sections. J Histochem Cytochem. 2002;50:463-72.

100. Sydow A, Van der Jeugd A, Zheng F, Ahmed T, Balschun D, Petrova O, et al. Tau-induced defects in synaptic plasticity, learning, and memory are reversible in transgenic mice after switching off the toxic Tau mutant. J Neurosci. 2011;31:2511-25. doi:10.1523/JNEUROSCI.5245-10.2011.
101. Takeda S, Wegmann S, Cho H, DeVos SL, Commins C, Roe AD, et al. Neuronal uptake and propagation of a rare phosphorylated high-molecularweight tau derived from Alzheimer's disease brain. Nat Commun. 2015;6: 8490. doi:10.1038/ncomms9490.

102. Tamguney G, Francis KP, Giles K, Lemus A, DeArmond SJ, Prusiner SB. Measuring prions by bioluminescence imaging. Proc Natl Acad Sci U S A. 2009;106:15002-6. doi:10.1073/pnas.0907339106.

103. Tarawneh R, Holtzman DM. The clinical problem of symptomatic Alzheimer disease and mild cognitive impairment. Cold Spring Harb Perspect Med. 2012;2:a006148. doi:10.1101/cshperspect.a006148.

104. Tatebayashi Y, Miyasaka T, Chui DH, Akagi T, Mishima K, Iwasaki K, et al. Tau filament formation and associative memory deficit in aged mice expressing mutant (R406W) human tau. Proc Natl Acad Sci U S A. 2002;99:13896-901. doi:10.1073/pnas.202205599202205599.

105. Tellez-Nagel I, Wisniewski HM. Ultrastructure of neurofibrillary tangles in Steele-Richardson-Olszewski syndrome. Arch Neurol. 1973;29:324-7.

106. Terry RD, Masliah E, Salmon DP, Butters N, DeTeresa R, Hill R, et al. Physical basis of cognitive alterations in Alzheimer's disease: synapse loss is the major correlate of cognitive impairment. Ann Neurol. 1991;30:572-80. doi:10.1002/ana.410300410.

107. Terwel D, Lasrado R, Snauwaert J, Vandeweert E, Van Haesendonck C, Borghgraef $\mathrm{P}$, et al. Changed conformation of mutant Tau-P301L underlies the moribund tauopathy, absent in progressive, nonlethal axonopathy of Tau-4R/2N transgenic mice. J Biol Chem. 2005;280:3963-73. doi:10.1074/jbc.M409876200.

108. Van der Jeugd A, Hochgräfe K, Ahmed T, Decker JM, Sydow A, Hofmann A, et al. Cognitive defects are reversible in inducible mice expressing proaggregant full-length human Tau. Acta Neuropathol. 2012;123:787-805. doi:10.1007/s00401-012-0987-3.

109. von Bergen M, Barghorn S, Li L, Marx A, Biernat J, Mandelkow EM, et al. Mutations of tau protein in frontotemporal dementia promote aggregation of paired helical filaments by enhancing local beta-structure. J Biol Chem. 2001;276:48165-74. doi:10.1074/jbc.M105196200.

110. Wang M-VM, Kruger U, Kaushik S, Wong E, Mandelkow EM, Cuervo AM, et al. Tau fragmentation, aggregation and clearance: the dual role of lysosomal processing. Hum Mol Genet. 2009;18:4153-70. doi:10.1093/hmg/ddp367.

111. Wes PD, Easton A, Corradi J, Barten DM, Devidze N, DeCarr LB, et al. Tau overexpression impacts a neuroinflammation gene expression network perturbed in Alzheimer's disease. PLoS One. 2014;9, e106050. doi:10.1371/journal.pone.0106050

112. Wolfe MS. The role of tau in neurodegenerative diseases and its potential as a therapeutic target. Scientifica (Cairo). 2012;2012:796024. doi:10.6064/2012/796024

113. Wszolek ZK, Slowinski J, Golan M, Dickson DW. Frontotemporal dementia and parkinsonism linked to chromosome 17. Folia Neuropathol. 2005;43: 258-70.

114. Yi JJ, Ehlers MD. Ubiquitin and protein turnover in synapse function. Neuron. 2005;47:629-32. doi:10.1016/j.neuron.2005.07.008.

115. Yirmiya R, Goshen I. Immune modulation of learning, memory, neural plasticity and neurogenesis. Brain Behav Immun. 2011;25:181-213. doi:10.1016/j.bbi.2010.10.015.

116. Yoshiyama Y, Higuchi M, Zhang B, Huang SM, Iwata N, Saido TC, et al. Synapse loss and microglial activation precede tangles in a P301S tauopathy mouse model. Neuron. 2007:53:337-51. doi:10.1016/j.neuron.2007.01.010.

117. Zhu L, Ramboz S, Hewitt D, Boring L, Grass DS, Purchio AF. Non-invasive imaging of GFAP expression after neuronal damage in mice. Neurosci Lett. 2004;367:210-2. doi:10.1016/j.neulet.2004.06.020.

118. Zimmer ER, Leuzy A, Benedet AL, Breitner J, Gauthier S, Rosa-Neto P. Tracking neuroinflammation in Alzheimer's disease: the role of positron emission tomography imaging. J Neuroinflammation. 2014;11:120. doi:10.1186/1742-2094-11-120. 